OPEN ACCESS

Edited by:

Hector A. Cabrera-Fuentes, University of Giessen, Germany

Reviewed by:

Flavio Andres Salazar Onfray,

University of Chile, Chile Marion E. G. Brunck,

Monterrey Institute of Technology and Higher Education (ITESM), Mexico

Di Yu,

Uppsala University, Sweden

*Correspondence: Oleg Markov markov_oleg@list.ru

Specialty section: This article was submitted to Translational Pharmacology, a section of the journal

Frontiers in Pharmacology

Received: 19 April 2019 Accepted: 06 September 2019 Published: 11 October 2019

Citation:

Markov O, Oshchepkova A and Mironova N (2019) Immunotherapy Based on Dendritic Cell-Targeted/-

Derived Extracellular Vesicles $-A$ Novel Strategy for Enhancement of the Anti-tumor Immune Response.

Front. Pharmacol. 10:1152.

doi: 10.3389/fphar.2019.01152

\section{Immunotherapy Based on Dendritic Cell-Targeted/-Derived Extracellular Vesicles-A Novel Strategy for Enhancement of the Anti-tumor Immune Response}

\author{
Oleg Markov *, Anastasiya Oshchepkova and Nadezhda Mironova
}

Laboratory of Nucleic Acids Biochemistry, Institute of Chemical Biology and Fundamental Medicine SB RAS, Novosibirsk, Russia

Dendritic cell (DC)-based anti-tumor vaccines have great potential for the treatment of cancer. To date, a large number of clinical trials involving DC-based vaccines have been conducted with a view to treating tumors of different histological origins. However, DC-based vaccines had several drawbacks, including problems with targeted delivery of tumor antigens to DCs and prolong storage of cellular vaccines. Therefore, the development of other immunotherapeutic approaches capable of enhancing the immunogenicity of existing DC-based vaccines or directly triggering anti-tumor immune responses is of great interest. Extracellular vesicles (EVs) are released by almost all types of eukaryotic cells for paracrine signaling. EVs can interact with target cells and change their functional activity by delivering different signaling molecules including mRNA, non-coding RNA, proteins, and lipids. EVs have potential benefits as natural vectors for the delivery of RNA and other therapeutic molecules targeted to DCs, T-lymphocytes, and tumor cells; therefore, EVs are a promising entity for the development of novel cell-free anti-tumor vaccines that may be a favourable alternative to DC-based vaccines. In the present review, we discuss the anti-tumor potential of EVs derived from DCs, tumors, and other cells. Methods of EV isolation are systematized, and key molecules carried by EVs that are necessary for the activation of a DC-mediated anti-tumor immune response are analyzed with a focus on the RNA component of EVs. Characteristics of anti-tumor immune responses induced by EVs in vitro and in vivo are reviewed. Finally, perspectives and challenges with the use of EVs for the development of anti-tumor cell-free vaccines are considered.

Keywords: dendritic cells, extracellular vesicles, exosomes, tumor, anti-tumor vaccines

\section{DENDRITIC CELLS: A BRIEF HISTORY OF ANTI-TUMOR DC-BASED VACCINE DEVELOPMENT}

The history of dendritic cells (DCs) began during the second half of the nineteenth century, when Paul Langerhans described for the first time star-shaped cells localized in the skin and mistakenly assumed a neuronal origin (Langerhans, 1868). Eventually, these cells were named Langerhans cells and were found to be a special skin resident subpopulation of DCs (Merad et al., 2008). DCs were rediscovered by Ralph M. Steinman and Zanvil A. Cohn a century later in 1973 (Steinman and 
Cohn, 1973), and this discovery eventually launched a new era in immunology. It was found that DCs are professional antigenpresenting cells, the main function of which is to capture, process, and present antigen material to $\mathrm{T}$ lymphocytes in complex with MHC I and II molecules, activating an antigenspecific T-lymphocyte immune response (Nussenzweig et al., 1980). It was understood how the antigen-specific T-cell immune response is triggered, and DCs were shown to play a principal role in this process (Dhodapkar et al., 1999).

Later, the method of generating a large number of DCs was developed on the basis of the incubation of monocyte and bone marrow DC progenitors in the presence of IL-4 and GM-CSF (Romani et al., 1994; Sallusto et al., 1995), which significantly facilitated investigations into the biology and immunotherapeutic potential of DCs. As a result of these studies, a novel type of immunotherapeutic anti-tumor vaccine was developed, namely, the DC-based vaccine (Constantino et al., 2016). Classically, this vaccine is based on DCs loaded with tumor antigens using different approaches ranging from passive loading of DCs with tumor proteins or peptides to transfection/transduction of DCs with nucleic acids (NAs)/viral vectors encoding tumor antigens (Palucka and Banchereau, 2013).

Several decades of intensive investigations of anti-tumor DC-based vaccines have revealed their high efficiency in various murine tumor models (Lin et al., 2015; Markov et al., 2017) and human xenografts in immunodeficient mice (Liu et al., 2019).

Now in clinical trials a great number of DC-based vaccines are explored (see revs. Van Willigen et al., 2018; MastelicGavillet et al., 2019). The first therapeutic anti-tumor DC-based vaccine, Sipuleucel-T, was approved by the U.S. Food and Drug Administration in 2010 for use in castration-resistant prostate tumors. Sipuleucel-T activates the immune response against the antigen, PAP/PA2024, and increases overall survival in patients (Kantoff et al., 2010); however, Sipuleucel-T is highly priced cellular product with technology challenging preparation process which required highly qualified personnel (Van Willigen et al., 2018).

The Indian government agency (CDSCO-Central Drugs Standard Control Organization) approved in 2017 vaccine based on an autologous monocyte-derived DC loaded with tumor lysate $\left(\mathrm{APCEDEN}^{\circledR}\right)$ for treatment of prostate, ovarian and colorectal cancers, and non-small cell lung carcinoma (Kumar et al., 2017). In phase II clinical trial this vaccine demonstrated well tolerance by patients with refractory solid malignancies (Bapsy et al., 2014) and a survival benefit over 100 days (Kumar et al., 2017).

Current ongoing clinical trials using personalized DC-based vaccines are conducted for treatment of ovarian cancer; brain tumors; advanced melanoma, colorectal cancer, lung cancer, and so on (Table 1). Types of vaccines studied in clinical trials are varied by the composition of DC-pulsed antigen that can be in the form of tumor lysate, tumor-derived peptides, and mRNA-encoding TAAs. Some types of DC-vaccines are prepared by fusion of DC with tumor cells. Introduction in the treatment regimen of additional components including chemotherapeutics (NCT01957956, 2013; NCT01946373, 2013; NCT02503150, 2015; Table 1), immune response modifiers (NCT01808820, 2013; NCT01204684, 2010; NCT00799110, 2008; Table 1), and immune checkpoint inhibitors
(NCT03014804, 2017; NCT02529072, 2015; NCT02678741, 2016; NCT03092453, 2017; NCT03152565, 2017; NCT03406715, 2018; Table 1), as well as cytokines providing the maturation of DC lead to the novel treatment schemes with enhanced efficacy. DC-based vaccines demonstrate their high potential, and some of them have already reached phase 3 of clinical trials: DC-vaccine loaded with tumor-derived RNA for treatment of uveal melanoma (NCT01983748, 2013, Table 1) and tumor-lysate pulsed DC-vaccine in combination with FOLFOX6 regiment for treatment of metastatic colorectal cancer (NCT02503150, 2015; Table 1).

The era of investigation of DC-derived membrane vesicles for immunotherapy of cancer is just beginning, and ongoing clinical trials are extremely scarce. For instance, a clinical trial of DC-derived extracellular vesicles (EVs) for treatment of patients with non-small cell lung cancer (NSCLC) is now completed (NCT01159288, 2010, Table 1). It was shown that DC-derived EVs exerted natural killer (NK) cell effector functions in patients with NSCLC, thus boosting the NK cell arm of antitumor immunity (Besse et al., 2016). These findings indicate the efficiency of novel immunotherapeutic anti-tumor approaches based on membrane vesicles and their great therapeutic prospects.

\section{EVS AS ALTERNATIVE CELL-FREE ANTI-TUMOR VACCINES}

One of anti-tumor immunotherapeutic approaches is the application of EVs of DCs and tumor cells. All types of eukaryotic cells produce nano-sized vesicles with the capacity to shuttle NAs, proteins, and lipids to other cells and participate in cellto-cell communication, thus realizing paracrine regulation. EVs are a heterogeneous population of membrane vesicles that are classified into three major groups according to their subcellular origin and size: apoptotic bodies, microvesicles (MVs), and exosomes (Gurunathan et al., 2019), the latter of which are the most studied. Exosomes are nano-sized vesicles originating from multivesicular bodies (MVBs) in the endosomal pathway, with sizes ranging from 50 to $150 \mathrm{~nm}$ in diameter and membranes characterized by a high content of cholesterol and glycosphingolipids (Colombo et al., 2014). MVs are described as 100 - to $1000-\mathrm{nm}$ vesicles enveloped from the cell surface membrane by direct budding (Morel et al., 2011). Since there exists no perfect method to isolate only exosomes (Chulpanova et al., 2018), studies on the functional activity of EVs have been performed on exosome- or MV-enriched populations or a mixture of both types of EVs. Therefore, in the present review, the common term EVs will be used to describe primarily exosomeenriched vesicles.

It has been demonstrated that EVs can participate in immune regulation, matrix remodeling, signaling pathways, intercellular exchange with oncoproteins and oncogenes, induction of angiogenesis, and preparation of a pre-metastatic niche (Lee et al., 2011). It is known that DC-derived EVs carry functionally active molecules on their surfaces that take part in immunological synapses-complexes of MHC class I and II with tumor antigens, as well as co-stimulatory and adhesion molecules (such as CD80, CD86, and CD40) - needed for the induction of anti-tumor T-cell 
TABLE 1 | Ongoing clinical trials of dendritic cell-based vaccines for treatment of various types of tumors.

\begin{tabular}{|c|c|c|c|c|c|c|}
\hline Type of tumor & $\begin{array}{l}\text { Type of TAA } \\
\text { pulsed to DC }\end{array}$ & Vaccine composition & $\begin{array}{l}\text { Primary / secondary } \\
\text { outcomes }\end{array}$ & Sponsor & Phase & NCT identifier \\
\hline \multicolumn{7}{|l|}{ Brain tumors } \\
\hline $\begin{array}{l}\text { newly diagnosed } \\
\text { glioblastoma }\end{array}$ & tumor lysate & $\begin{array}{l}\text { DC-vaccine/ } \\
\text { temozolomide* }\end{array}$ & $\begin{array}{l}\text { Toxicity/ Clinical benefit rate, } \\
\text { duration of response, overall } \\
\text { response rate }\end{array}$ & $\begin{array}{l}\text { Mayo Clinic, } \\
\text { National Cancer } \\
\text { Institute (NCI), USA }\end{array}$ & early phase 1 & $\begin{array}{l}\text { NCT01957956, } \\
2013\end{array}$ \\
\hline $\begin{array}{l}\text { recurrent } \\
\text { glioblastoma }\end{array}$ & tumor lysate & DC-vaccine & $\begin{array}{l}\text { Toxicity/ Clinical benefit rate, } \\
\text { duration of response, overall } \\
\text { response rate, OS, PFS, time } \\
\text { to response }\end{array}$ & & early phase 1 & $\begin{array}{l}\text { NCT03360708, } \\
2017\end{array}$ \\
\hline $\begin{array}{l}\text { malignant glioma/ } \\
\text { glioblastoma, }\end{array}$ & tumor lysate & $\begin{array}{l}\text { DC-vaccine/ } \\
\text { Imiquimod }^{\star \star}\end{array}$ & Adverse events/ OS, PFS, IR & $\begin{array}{l}\text { Macarena De La } \\
\text { Fuente, University } \\
\text { of Miami, USA }\end{array}$ & Phase 1 & $\begin{array}{l}\text { NCT01808820, } \\
2013\end{array}$ \\
\hline $\begin{array}{l}\text { glioma/ astrocytoma/ } \\
\text { astrodendroglioma/ } \\
\text { glioblastoma }\end{array}$ & tumor lysate & $\begin{array}{l}\text { DC-vaccine + } \\
0.2 \% \text { resiquimod }{ }^{\star *} / \\
\text { autologous DC-vaccine } \\
\text { + poly ICLC } \#\end{array}$ & $\begin{array}{l}\text { Most effective combination of } \\
\text { DC vaccine components/ Time } \\
\text { to tumor progression, OS }\end{array}$ & $\begin{array}{l}\text { Jonsson } \\
\text { Comprehensive } \\
\text { Cancer Center, } \\
\text { USA }\end{array}$ & Phase 2 & $\begin{array}{l}\text { NCT01204684, } \\
2010\end{array}$ \\
\hline $\begin{array}{l}\text { recurrent } \\
\text { glioblastoma }\end{array}$ & tumor lysate & $\begin{array}{l}\text { DC-vaccine/ } \\
\text { Nivolumab\$ }\end{array}$ & $\begin{array}{l}\text { Adverse events, OS/ PFS, QoL, } \\
\text { CR, PR, SD, PD, RSDR }\end{array}$ & & Phase 2 & $\begin{array}{l}\text { NCT03014804, } \\
2017\end{array}$ \\
\hline $\begin{array}{l}\text { recurrent malignant } \\
\text { glioma/ astrocytoma/ } \\
\text { glioblastoma }\end{array}$ & $\begin{array}{l}\text { CMV pp65- } \\
\text { LAMP mRNA }\end{array}$ & $\begin{array}{l}\text { DC-vaccine/ } \\
\text { Nivolumab }^{\$}\end{array}$ & Safety/ OS, PFS & $\begin{array}{l}\text { Gary Archer Ph.D., } \\
\text { Duke University, } \\
\text { USA }\end{array}$ & Phase 1 & $\begin{array}{l}\text { NCT02529072, } \\
2015\end{array}$ \\
\hline glioblastoma & & $\begin{array}{l}\text { DCs/ autologous } \\
\text { lymphocytes/ tetanus } \\
\text { toxoid }\end{array}$ & $\begin{array}{l}\text { Feasibility, safety/ humoral and } \\
\text { cellular IR, time to progression }\end{array}$ & & Phase 1 & $\begin{array}{l}\text { NCT00639639, } \\
2008\end{array}$ \\
\hline \multicolumn{7}{|l|}{ Melanoma } \\
\hline malignant melanoma & tumor lysate & $\begin{array}{l}\text { DC-vaccine/ T-cells/ } \\
\text { cyclophosphamide*/ } \\
\text { fludorabine* }\end{array}$ & $\begin{array}{l}\text { Safety/ Time to disease } \\
\text { progression }\end{array}$ & $\begin{array}{l}\text { Karolinska } \\
\text { University Hospital, } \\
\text { Sweden }\end{array}$ & Phase 1 & $\begin{array}{l}\text { NCT01946373, } \\
2013\end{array}$ \\
\hline metastatic melanoma & tumor lysate & $\begin{array}{l}\text { TLPLDC-vaccine }{ }^{@ /} \\
\text { Checkpoint inhibitors }\end{array}$ & $\begin{array}{l}\text { Safety/ Tumor response to } \\
\text { treatment }\end{array}$ & $\begin{array}{l}\text { Cancer Insight, } \\
\text { LLC, USA }\end{array}$ & $\begin{array}{l}\text { Phase 1/ } \\
\text { Phase } 2\end{array}$ & $\begin{array}{l}\text { NCT02678741, } \\
2016\end{array}$ \\
\hline melanoma & & TLPLDC-vaccine ${ }^{@}$ & Disease free survival & & Phase 2 & $\begin{array}{l}\text { NCT02301611, } \\
2014\end{array}$ \\
\hline \multirow[t]{2}{*}{$\begin{array}{l}\text { malignant melanoma } \\
\text { Stage III/ Stage IV }\end{array}$} & tumor lysate & DC-vaccine/RT/IFN- $a$ & $\begin{array}{l}\text { Safety, tolerability, feasibility, } \\
\text { irDCR, IR / OS, irTTP, irORR, } \\
\text { irDOR, irTTR, irPFS }\end{array}$ & $\begin{array}{l}\text { Istituto Scientifico } \\
\text { Romagnolo per lo } \\
\text { Studio e la cura dei }\end{array}$ & Phase 2 & $\begin{array}{l}\text { NCT01973322, } \\
2013\end{array}$ \\
\hline & & DC-vaccine & RFS/OS, IR & Tumouri, Italy & Phase 2 & $\begin{array}{l}\text { NCT02718391, } \\
2016\end{array}$ \\
\hline advanced melanoma & $\begin{array}{l}\text { tumor-derived } \\
\text { peptide }\end{array}$ & 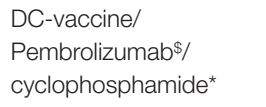 & $\begin{array}{l}\mathrm{IR} / \text { Clinical response, time to } \\
\text { progression, safety, adverse } \\
\text { events }\end{array}$ & $\begin{array}{l}\text { University of } \\
\text { Pennsylvania, USA }\end{array}$ & Phase 1 & $\begin{array}{l}\text { NCT03092453, } \\
2017\end{array}$ \\
\hline uveal melanoma & $\begin{array}{l}\text { tumor-derived } \\
\text { RNA }\end{array}$ & DC-vaccine & $\begin{array}{l}\text { Prolongation of disease free } \\
\text { survival/ OS, IR }\end{array}$ & $\begin{array}{l}\text { University Hospital } \\
\text { Erlangen, Germany }\end{array}$ & Phase 3 & $\begin{array}{l}\text { NCT01983748, } \\
2013\end{array}$ \\
\hline \multicolumn{7}{|l|}{ Colorectal cancer } \\
\hline colorectal cancer & $\begin{array}{l}\text { tumor- } \\
\text { associated } \\
\text { antigen CEA }\end{array}$ & DC vaccine & $\begin{array}{l}\text { Safety, feasibility/ Antigen- } \\
\text { specific IR, pathological } \\
\text { responses, disease-free } \\
\text { survival }\end{array}$ & $\begin{array}{l}\text { Radboud University, } \\
\text { Netherlands }\end{array}$ & $\begin{array}{l}\text { Phase 1/ } \\
\text { Phase } 2\end{array}$ & $\begin{array}{l}\text { NCT01885702, } \\
2013\end{array}$ \\
\hline $\begin{array}{l}\text { metastatic colorectal } \\
\text { cancer }\end{array}$ & tumor lysate & $\begin{array}{l}\text { DC-vaccine/ } \\
\text { FOLFOX6§ }\end{array}$ & $\begin{array}{l}\text { PFS/ Objective response, OS, } \\
\text { QoL, adverse events }\end{array}$ & $\begin{array}{l}\text { Second Military } \\
\text { Medical University, } \\
\text { China }\end{array}$ & Phase 3 & $\begin{array}{l}\text { NCT02503150, } \\
2015\end{array}$ \\
\hline colorectal cancer & tumor lysate & $\begin{array}{l}\text { DC-vaccine/ } \\
\text { Avelumab\$ }\end{array}$ & $\begin{array}{l}\text { Dosed of Avelumab and } \\
\text { DCs, PFS/ Adverse events, } \\
\text { immunophenotype of tumors, } \\
\text { MSS, RAS and BRAF mutation } \\
\text { status }\end{array}$ & $\begin{array}{l}\text { Grupo Espanol } \\
\text { Multidisciplinario del } \\
\text { Cancer Digestivo, } \\
\text { Spain }\end{array}$ & $\begin{array}{l}\text { Phase 1/ } \\
\text { Phase } 2\end{array}$ & $\begin{array}{l}\text { NCT03152565, } \\
2017\end{array}$ \\
\hline \multicolumn{7}{|l|}{ Ovarian cancer } \\
\hline ovarian cancer & tumor lysate & DC vaccine /ontak\& & IR/ Toxicity & $\begin{array}{l}\text { Loyola University, } \\
\text { USA }\end{array}$ & Phase 2 & $\begin{array}{l}\text { NCT00703105, } \\
2008\end{array}$ \\
\hline $\begin{array}{l}\text { ovarian cancer } \\
\text { primary peritoneal } \\
\text { cancer } \\
\text { fallopian tube cancer }\end{array}$ & - & $\begin{array}{l}\text { DC-tumor fusion } \\
\text { vaccine/ GM-CSF, } \\
\text { imiquimod }^{* *}\end{array}$ & IR/ Toxicity, clinical response & $\begin{array}{l}\text { Beth Israel } \\
\text { Deaconess Medical } \\
\text { Center, Israel }\end{array}$ & Phase 2 & $\begin{array}{l}\text { NCT00799110, } \\
2008\end{array}$ \\
\hline
\end{tabular}


TABLE 1 | Continued

\begin{tabular}{|c|c|c|c|c|c|c|}
\hline Type of tumor & $\begin{array}{l}\text { Type of TAA } \\
\text { pulsed to DC }\end{array}$ & Vaccine composition & $\begin{array}{l}\text { Primary / secondary } \\
\text { outcomes }\end{array}$ & Sponsor & Phase & NCT identifier \\
\hline \multicolumn{7}{|l|}{ Lung cancer } \\
\hline Small-cell lung cancer & - & $\begin{array}{l}\text { DC endogenously } \\
\text { expressed p53 gene/ } \\
\text { Ipilimumab, Nivolumab\$ }\end{array}$ & DCR/ PFS, OS, ORR, IR & $\begin{array}{l}\text { H. Lee Moffitt } \\
\text { Cancer Center and } \\
\text { Research Institute }\end{array}$ & Phase 2 & $\begin{array}{l}\text { NCT03406715, } \\
2018\end{array}$ \\
\hline $\begin{array}{l}\text { Non-small cell lung } \\
\text { cancer }^{\odot}\end{array}$ & $\begin{array}{l}\text { peptides } \\
\text { PRS pan-DR, } \\
\text { MAGE-3 DP04, } \\
\text { MAGE-1 A2, } \\
\text { MAGE-3 A2, } \\
\text { NY-ESO-1 A2 et } \\
\text { MART-1 A2 }\end{array}$ & DC-derived exosomes & PFS & $\begin{array}{l}\text { Gustave Roussy, } \\
\text { Cancer Campus, } \\
\text { Grand Paris, France }\end{array}$ & Phase 2 & $\begin{array}{l}\text { NCT01159288, } \\
2010\end{array}$ \\
\hline
\end{tabular}

*chemotherapeutic; **immune response modifier; "poly ICLC, interstitial Cajal-like cells, TLR3 agonist; \$monoclonal antibodies, immune checkpoint inhibitor; \&anti CD25 denileukin

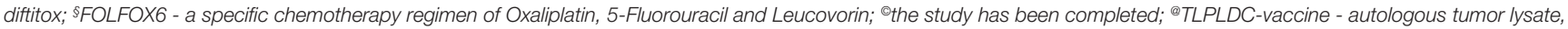
particle-loaded, dendritic cell vaccine;

OS, overall survival; PFS, progression free survival; QoL, quality of life; CR, number of participants with complete response; PR, number of participants with partial response; $S D$, number of participants with stable disease; PD, number of participants with progressive disease; RSDR, response/stable disease rate; RFS, relapse-free survival; irDCR, immune related disease control rate; irTTP, immuno-related time to progression; irORR, immuno-related overall response rate; irDOR, immuno-related duration of response; irTTR, immuno-related time to response; irPFS, immuno-related progression free survival; DCR, disease control rate; ORR, overall response rate; IR, immune response; $R T$, radiation treatment.

immune responses (Munich et al., 2012). In addition, tumor cellderived EVs have been shown to have an immunostimulatory effect on anti-tumor DCs (André et al., 2002; Liu et al., 2018); hence, the application of both DC- and tumor cell-derived EVs as novel immunotherapeutic cell-free anti-tumor vaccines has great potential. Together with their highly therapeutic antitumor potential, cell-free vaccines based on EVs have advantages over classical DCs involved: (1) EV-based vaccines can be stored for a prolonged time without loss of immunotherapeutic activity (Jeyaram and Jay, 2018); (2) the more efficient capture of EVs rather than the soluble molecules of antigen-presenting cells (Zeelenberg et al., 2008). Undoubtedly, the use of EVs as antitumor vaccines possesses great potential and relevance (Viaud et al., 2010; Pitt et al., 2016).

\section{METHODS OF EV ISOLATION}

The most commonly described method in the literature for the isolation of EVs is sequential centrifugation of conditioned medium samples or biological fluids (blood serum, urine, milk, etc.) (Petersen et al., 2014). Typically, low speeds with increasing centrifugal force are used to remove cells, cell debris, and large particles, followed by ultracentrifugation at $100,000 \mathrm{~g}$ to $120,000 \mathrm{~g}$ for at least 60 to $120 \mathrm{~min}$ to precipitate EVs (see studies in Table 2). This method is relatively laborious, timeconsuming, and requires special expensive equipment (Soung et al., 2017). The high heterogeneity of EVs and overlapping size with protein aggregates, as well as the need for several rounds of ultracentrifugation during the wash steps of EVs, inevitably results in EV loss, contamination, and low yields (Li et al., 2017). The widely used ultracentrifugation method for EV isolation results in the lowest recovery of particles; nevertheless, it is the most popular approach to date (Tang et al., 2017).
To increase the enrichment and purity of isolated EVs, centrifugation using a sucrose density gradient or sucrose cushion, in addition to ultrafiltration, is used in combination with ultracentrifugation or alone (Dai et al., 2008; Bu et al., 2011; Besse et al., 2016; Diamond et al., 2018; Guo et al., 2018). Sucrosebased density gradient ultracentrifugation of EVs allows isolation of the pure fraction of EVs due to their specific buoyant densityexosomes float in a sucrose gradient of 1.13 to $1.19 \mathrm{~g} / \mathrm{mL}$ (Théry et al., 2002). The ultrafiltration method sequentially removes larger particles from samples, with a final ultrafiltration step using a $100-\mathrm{kDa}$ MWCO filter, such as Centricon Plus-70, Centriplus, or Amicon Ultra (Millipore). This method is rapid and technically easy but allows isolation of EVs with high purity. Furthermore, a combination of filtration and sucrose-based density gradient centrifugation has made it possible to efficiently isolate high purity EVs in sufficient amounts for clinical trials (Escudier et al., 2005; Morse et al., 2005).

Easy-to-use commercial kits, such as ExoQuick (System biosciences) (Rekker et al., 2014) or the Total Exosome Isolation Kit (Invitrogen) (Wang et al., 2015), are rarely used to isolate DC-derived EVs. The principle of such kits is salting out EVs from samples by the addition of water-excluding polymers, such as polyethylene glycol (PEG), which occupy water molecules and force less soluble components, including EVs, out of the solution (Li et al., 2017). Following overnight incubation at $4^{\circ} \mathrm{C}$, precipitated EVs are isolated by short centrifugation steps at low speed (up to $10,000 \mathrm{~g}$ ). The advantages of commercial kits are less time-consuming method, possibility to isolate EVs from small volumes of medium, no need for special expensive instruments, such as an ultracentrifuge, and no technical challenges (Helwa et al., 2017). However, the main drawback of this method is the isolation of non-vesicular particles together with EVs (Yamada et al., 2012), which is the reason why this method is less frequently used. 
TABLE 2 | Efficiency of antitumour vaccines on the base of tumour cell-/DC-derived EVs in animal tumour models in vivo, human cells ex vivo and in clinical trials.

A. Vaccines on the base of tumour cell-derived DC-targeted EVs.

\begin{tabular}{|c|c|c|c|c|c|}
\hline EV origin & $\begin{array}{l}\text { Isolation } \\
\text { method }\end{array}$ & $\begin{array}{l}\text { Carried/loaded } \\
\text { molecules }\end{array}$ & $\begin{array}{l}\text { Strategy of } \\
\text { loading }\end{array}$ & Biological outcome & Reference \\
\hline $\begin{array}{l}\text { Murine } \\
\text { H22 hepatocarcinoma } \\
\text { B16 melanoma } \\
\text { CT26 colon carcinoma }\end{array}$ & $\begin{array}{l}\text { Sequential } \\
\text { centrifugation }\end{array}$ & DNA fragments & & $\begin{array}{l}\text { Ex vivo } \\
\text { Tumour-derived MVs were efficiently captured by } \\
\text { DCs, stimulated DCs via cGAS/STING signaling } \\
\rightarrow \text { activation of type I IFN production by DCs } \\
\rightarrow \text { DC maturation and presentation of tumour } \\
\text { antigens to T cells. }\end{array}$ & Zhang et al., 2014a \\
\hline
\end{tabular}

antigens to $T$ cells.

$\begin{array}{ll}\text { Murine leukemia L1210 } & \text { Sequential } \\ \text { Human leukemia K562 } & \text { centrifugation }\end{array}$

Human glioma

Murine malignant

mesothelioma AB1

Murine myeloid leukemia WEHI3B

Murine EG7-OVA

Iymphoma
Sequential

centrifugation

Sequential

centrifugation

\section{In vivo $\mathrm{H} 22$ hepatocarcinoma, B16}

\section{melanoma, СT26 colon carcinoma}

Vaccination (SC) of mice with microvesicles (MVs)

activated protective immune response against

tumours.

Vaccination (SC) of mice with DCs loaded with

MVs activated efficient antitumour therapeutic

response.

MVs were more immunogenic in comparison with exosomes

\section{Ex vivo}

DCs loaded with tumour-derived EVs (DC/EVs)

induced antileukemic CTLs more efficiently than

EVs alone.

\section{In vivo L1210 leukemia model}

Prophylactic vaccination (SC) of mice with DC/

EVs provided protection of $70-100 \%$ of mice

against tumour development.

Therapeutic vaccination (SC) of tumour-

bearing mice with $\mathrm{DC} / \mathrm{EV}$ s resulted in complete

regression of tumours.

\section{Ex vivo}

DCs/EVs activated glioma-specific CTLs ex vivo that lysed glioma cells 2-fold more efficiently as compared to tumour lysate-pulsed DCs.

\section{In vivo $\mathrm{AB1}$ mesothelioma model}

Vaccination of tumour-bearing mice with DC/

EVs increased median and overall survival as compared to vaccination with tumour lysateloaded DCs (median survival 29.5 or 18.5 days, respectively; overall survival $33.3 \%$ or $16.7 \%$, respectively).

In vivo WEHI3B myeloid leukemia model

DC/EVs vaccination of tumour-bearing mice resulted in more significant retardation of tumour growth and survival in animals as compared with tumour lysate-loaded DCs.

DC/EVs stimulated trogocytosis and proliferation of CD4 ${ }^{+} \mathrm{T}$ cells.

In vivo BL6-10-OVA melanoma model

Prophylactic vaccination (IV) of mice:

EVs - 4/8 mice with tumours, 29 metastases

DC/EVs - 1/8 mice with tumours, 5 metastases

DC/OVA - 0/8 mice with tumours, 0 metastases.
Yao et al., 2014

Bu et al., 2011

Mahaweni et al.,

2013

Gu et al., 2015

Yao et al., 2013 
TABLE 2 | Continued

A. Vaccines on the base of tumour cell-derived DC-targeted EVs.

\begin{tabular}{|c|c|c|c|c|c|}
\hline EV origin & $\begin{array}{l}\text { Isolation } \\
\text { method }\end{array}$ & $\begin{array}{l}\text { Carried/loaded } \\
\text { molecules }\end{array}$ & $\begin{array}{l}\text { Strategy of } \\
\text { loading }\end{array}$ & Biological outcome & Reference \\
\hline $\begin{array}{l}\text { Murine 3LL Lewis lung } \\
\text { carcinoma }\end{array}$ & $\begin{array}{l}\text { Sequential } \\
\text { centrifugation } \\
\text { with sucrose } \\
\text { gradient } \\
\text { centrifugation }\end{array}$ & CD40L & Indirect & $\begin{array}{l}\text { Ex vivo } \\
\text { CD4OL-EVs were more immunogenic as } \\
\text { compared with unmodified EVs: } \\
\text { CD4OL-EVs induced } \uparrow \text { mature DC phenotype and } \\
\uparrow \text { levels of IL-12 and TNF- } \alpha \text { synthesis by DCs. } \\
\text { DC/CD4OL-EVs induced } \uparrow \text { proliferation of } \\
\text { allogeneic T cells. } \\
\text { CD4OL-EVs induced } \uparrow \text { proliferation of tumour } \\
\text { antigen-specific CD4+ T cells. }\end{array}$ & Wang et al., 2014 \\
\hline
\end{tabular}

\section{In vivo 3LL Lewis lung carcinoma model}

Retardation of tumour growth; overall survival:

A. Prophylactic vaccination (SC).

CD40L-EVs - in 16 times; 80\%.

EVs - in 3 times; $50 \%$.

B. Therapeutic vaccination (SC).

CD40L-EVs - in 10 times; 50\%.

EVs - in 1.7 times; 0\%.

Human A549 non-small cell lung cancer

Sequential

centrifugation

Murine L1210 leukemia cells

Sequential centrifugation

Murine TSA breast carcinoma cells (irradiated)

$\begin{array}{ll}\begin{array}{l}\text { Sequential } \\ \text { centrifugation }\end{array} & \text { Degrading cytosoli Indirect } \\ \text { with sucrose } & \\ \text { gradient } & \\ \text { centrifugation } & \end{array}$

\section{Ex vivo}

Rab27-EVs upregulated MHC II, CD80, CD86 on DCs and stimulated synthesis of IL-1 $\beta$, TNF- $\alpha$ and RANTES by DCs.

DC/Rab27-EVs significantly $\uparrow$ CD4 ${ }^{+} \top$ cell proliferation.

\section{In vivo A549 xenograft model}

Rab27-EVs significantly $\downarrow$ tumour growth in both prophylactic and therapeutic settings in comparison with EVs (SC vaccination). Rab27-EVs activated Th1 immune response splenocytes of mice vaccinated with Rab27-EVs expressed $\uparrow$ levels of IL-2 and IFN- $\gamma$.

\section{Ex vivo}

shRNA-TGF- $\beta 1$-EVs promote maturation of DCs via $\downarrow$ TGF- $\beta 1$ expression.

DC/shRNA-TGF- $\beta 1$-EVs more efficiently promoted:

1) CD4+ $T$ cell proliferation;

2) Th1 cytokine secretion;

3) Efficient antileukemia CTL response;

as compared with DC/EVs.

\section{In vivo L1210 leukemia model}

Vaccination (SC) of mice with DC/shRNA-TGF$\beta 1-E V s$ in both prophylactic and therapeutic settings resulted in more significant inhibition of tumour growth in comparison with DC/EVs.

\section{Ex vivo} dsDNA-EVs stimulated maturation of DCs $-\uparrow$ CD40, CD80, CD86 expression and STINGdependent activation of IFN- $\beta$ synthesis.

\section{In vivo TSA breast carcinoma model} Prophylactic vaccination (SC) dsDNA-EVs elicited tumour-specific CD8 ${ }^{+} \mathrm{T}$ cell response that more significantly protected mice from tumour development (2/6 mice without tumours, tumours infiltrated with tumour antigenspecific CD8+ T cells) in comparison with EVs (0/6 mice without tumours).
Li et al., 2013

Huang et al., 2017

Diamond et al., 2018 
TABLE 2 | Continued

A. Vaccines on the base of tumour cell-derived DC-targeted EVs.

\begin{tabular}{|c|c|c|c|c|c|}
\hline EV origin & $\begin{array}{l}\text { Isolation } \\
\text { method }\end{array}$ & $\begin{array}{l}\text { Carried/loaded } \\
\text { molecules }\end{array}$ & $\begin{array}{l}\text { Strategy of } \\
\text { loading }\end{array}$ & Biological outcome & Reference \\
\hline $\begin{array}{l}\text { Murine B16BL6 } \\
\text { melanoma }\end{array}$ & $\begin{array}{l}\text { Sequential } \\
\text { centrifugation }\end{array}$ & $\begin{array}{l}\text { pH-sensitive } \\
\text { fusogenic GALA } \\
\text { peptide }\end{array}$ & Indirect & $\begin{array}{l}\text { Ex vivo } \\
\text { GALA-EVs efficiently delivered EV cargo to the } \\
\text { cytosol of } \\
\text { DCs. } \\
\text { DC/GALA-EVs showed } \uparrow \text { tumour antigen } \\
\text { presentation by MHC class I molecules. }\end{array}$ & Morishita et al., 2017 \\
\hline
\end{tabular}

Murine B16BL6 melanoma

$$
\begin{aligned}
& \text { Sequential } \\
& \text { centrifugation }
\end{aligned}
$$

Sequential centrifugation

3LL Lewis lung carcinoma
Human gastric adenocarcinoma (from ascites)
Sequential centrifugation Sucrose centrifugation

Sequential centrifugation Sucrose centrifugation
HSP60, HSP70

HSP70

cancer

Mouse MC38 colon
$\mathrm{CCL} 2, \mathrm{CCL} 3, \mathrm{CCL} 4$ CCL5, CCL20

Indirect

SAV-LA-EVs + biotinylated CpG-DNA $\rightarrow$ CpG-EVs

DC2.4/CpG-EVs - $\uparrow$ synthesis of TNF- $\alpha$, IL-6,

IL-12p40; $\uparrow$ tumour antigen presentation.

\section{In vivo B16BL6 melanoma model}

CpG-EVs vaccination (ID or IT) resulted in $\uparrow$ antitumour immune response as compared with EVs+CpG-DNA:

Prophylactic settings -3.7 times $\uparrow$ retardation of tumour growth.

Therapeutic settings -3.3 times $\uparrow$ retardation of tumour growth.

Survival -10 days $\uparrow$.

Number of lung metastases -6 times $\downarrow$.

Heat stressed EVs (HS-EVs).

HS-EVs chemoattracted CD11+ DCs and CD4+/ $\mathrm{CD}^{+} \mathrm{T}$ cells in vitro and in vivo.

In vivo 3LL Lewis lung carcinoma model

IT injection of HS-EVs induced more efficient specific antitumour response in comparison with EVs - $\downarrow$ tumour growth, $\uparrow$ survival.

\section{Heat stress improved the immunogenicity} of EVs.

HS-EVs promote DC maturation, $\uparrow$ IL-12p70 and TNF- $\alpha$ by DCs in comparison with EVs. HS-EVs activated proliferation of T cells. HS-EVs induced tumour-specific CTL response in vitro

DCs treated with HS-EVs stimulated conversation of Treg to Th17 cells.

\section{In vivo MC38 colon cancer model}

Therapeutic settings

IT vaccination of mice with $\mathrm{HS}-\mathrm{EV} s \rightarrow \mathrm{HSP} 70$

on HS-EVs stimulated secretion of IL- 6 by DCs

$\rightarrow$ IL-6 blocked differentiation of TGF- $\beta$-induced Treg cells and promotes Th17 cell differentiation ( $\uparrow \mathrm{LL}-17$ expression) in vitro and in vivo $\rightarrow \mathrm{IL}-17$ causes rejection of established prostate tumours in mice.

Inhibition of tumour growth by HS-EVs is completely dependent upon IL-6 and partially upon IL-17.

\section{Colorectal cancer patients}

In colorectal cancer patients treated with hyperthermia Tregs conversed to Th17 (in blood serum higher serum levels of IL-6 and IL-17; $\uparrow$ Th17 cells and $\downarrow$ Tregs in PBMC after hyperthermia). 
TABLE 2 | Continued

B. Vaccines on the base of DC-derived EVs.

\begin{tabular}{|c|c|c|c|}
\hline EV origin & $\begin{array}{l}\text { Isolation } \\
\text { method }\end{array}$ & $\begin{array}{l}\text { Carried/loaded } \\
\text { molecules }\end{array}$ & $\begin{array}{l}\text { Strategy } \\
\text { loading }\end{array}$ \\
\hline $\begin{array}{l}\text { Murine } \\
\text { DC2.4 } \\
\text { Bone marrow-derived } \\
\text { DCs (BM-DCs) }\end{array}$ & $\begin{array}{l}\text { Sequential } \\
\text { centrifugation }\end{array}$ & $a$-fetoprotein (AFP) & Indirect \\
\hline
\end{tabular}

\section{In vivo Hepa1-6 and autochtonous hepatocellular carcinoma (ectopic, orthotopic, carcinogen-induced)} models

AFP-EVs activated efficient tumour antigenspecific immune response that causes: $\uparrow$ retardation of tumour growth; $\uparrow$ overall survival.

AFP-EVs reshaped tumour immune microenvironment:

$\uparrow$ IFN- $\gamma$-expressing CD8 ${ }^{+} \uparrow$ cells;

$\uparrow$ levels of IFN- $\gamma$ and IL-2;

$\downarrow$ CD25+Foxp3+ Treg cells;

$\downarrow$ levels of IL-10 and TGF- $\beta$.

Poly(l:C) dramatically increased the potent antitumour immunity induced by E7 ${ }_{49-57}$-EVs.

\section{Ex vivo}

$E 7_{49-57}$-EVs efficiently induced anti-TC1 cervical cancer CTLs, activated proliferation of CD8 ${ }^{+} T$ cells and IFN- $\gamma$ synthesis.

\section{In vivo TC-1 cervical cancer model \\ Prophylactic and therapeutic settings \\ $\mathrm{E7}_{49-57}$-EVs vaccination (IV) resulted in activation of antitumour immune response in both treatment regimens. \\ poly(l:C)-E7 ${ }_{49-57}-E$ S vaccination markedly inhibited tumour growth and improved the overall survival rate ( $60 \%$ of mice).}

\section{Ex vivo}

DC/CRCL-GL261-EVs promote proliferation of $\mathrm{CD} 4^{+}$and $\mathrm{CD} 8^{+} \mathrm{T}$ cells and anti-GL261 glioma CTL activity as compared with DC/ GL261-EVs.

\author{
In vivo GL261 glioma model \\ Therapeutic settings \\ Vaccination of tumour-bearing mice with $\mathrm{DC} /$ \\ CRCL-GL261-EVs: \\ $\uparrow$ survival of tumour-bearing mice and $\downarrow$ \\ tumour growth; \\ $\uparrow$ infiltration of $\mathrm{CD} 4^{+}$and $\mathrm{CD} 8^{+} \uparrow$ cells into \\ intracranial glioma tissues; \\ $\uparrow$ production of IL-2 and IFN- $\gamma$. \\ Depletion of $\mathrm{CD}^{+}$and $\mathrm{CD} 8^{+} \mathrm{T}$ cells \\ significantly $\downarrow$ antitumour effect of DC/ \\ CRCL-GL261-EVs.
}

DC/CRCL-GL261-EVs downregulated Cbl-b and $\mathrm{c}-\mathrm{Cb}$ s signaling in T cells $\rightarrow$ activation of PI3K/Akt and ERK signaling in T cells.

\section{Reference}

Lu et al., 2017

Chen et al., 2018 
TABLE 2 | Continued

B. Vaccines on the base of DC-derived EVs.

\begin{tabular}{|c|c|c|c|c|c|}
\hline EV origin & $\begin{array}{l}\text { Isolation } \\
\text { method }\end{array}$ & $\begin{array}{l}\text { Carried/loaded } \\
\text { molecules }\end{array}$ & $\begin{array}{l}\text { Strategy of } \\
\text { loading }\end{array}$ & Biological effects & Reference \\
\hline $\begin{array}{l}\text { Human umbilical cord } \\
\text { blood-derived DCs }\end{array}$ & $\begin{array}{l}\text { Sequential } \\
\text { centrifugation }\end{array}$ & $\begin{array}{l}\text { Total tumour RNA } \\
\text { and tumour lysate } \\
\text { (human gastric } \\
\text { adenocarcinoma } \\
\text { BGC823) }\end{array}$ & Indirect & $\begin{array}{l}\text { Ex vivo } \\
\text { DCs transfected with total RNA isolated from } \\
\text { BGC823 human gastric adenocarcinoma cells } \\
\text { and EVs from these DCs stimulated more } \\
\text { potent proliferation of T cells and antitumour } \\
\text { CTLs in comparison with tumour lysate-loaded } \\
\text { DCs and EVs. } \\
\text { In vivo BGC823 human gastric } \\
\text { adenocarcinoma xenograft model } \\
\text { Therapeutic settings (PT vaccination) } \\
\text { DC/tumour RNA, DC/tumour lysate, tumour } \\
\text { RNA-EVs and tumour lysate-EVs injected } \\
\text { together with T cells significantly } \downarrow \text { tumour } \\
\text { growth in } 6.7 \text { times in comparison with } \\
\text { unvaccinated group of mice. }\end{array}$ & Guan et al., 2014 \\
\hline Murine BM-DCs & $\begin{array}{l}\text { Sequential } \\
\text { centrifugation }\end{array}$ & $\begin{array}{l}\text { HER2/neu-MHC I } \\
\text { HER2-MHC I }\end{array}$ & Indirect & 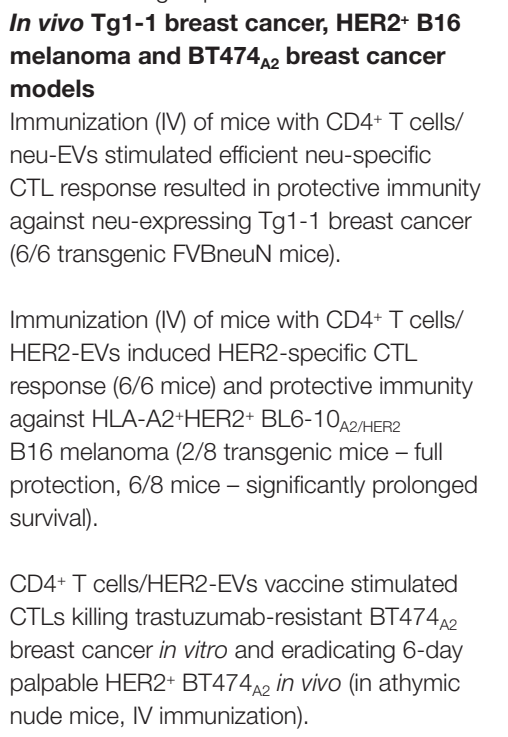 & Wang et al., 2013 \\
\hline Murine BM-DCs & $\begin{array}{l}\text { Sequential } \\
\text { centrifugation }\end{array}$ & $\begin{array}{l}\text { OVA } \\
\text { SIINFEKL }\end{array}$ & Indirect & $\begin{array}{l}\text { In vivo B16-OVA melanoma model } \\
\text { Prophylactic settings } \\
\text { CD8+ T cell response was induced in mice } \\
\text { immunized (IV) with OVA-EVs (but not with } \\
\text { SIINFEKL-EVs). } \\
\text { CTL response activated with OVA-EVs } \\
\text { was totally dependent on CD4+ T cells } \\
\text { and additionally on B cells (full OVA protein } \\
\text { contains both Th and B cell epitopes). } \\
\text { OVA-EVs were superior in protecting mice } \\
\text { against B16-OVA melanoma growth in } \\
\text { comparison with SIINFEKL-EVs. }\end{array}$ & Naslund et al., 2013 \\
\hline
\end{tabular}


TABLE 2 | Continued

B. Vaccines on the base of DC-derived EVs.

\begin{tabular}{lllll}
\hline EV origin & $\begin{array}{l}\text { Isolation } \\
\text { method }\end{array}$ & $\begin{array}{l}\text { Carried/loaded } \\
\text { molecules }\end{array}$ & $\begin{array}{l}\text { Strategy of } \\
\text { loading }\end{array}$ & Biological effects \\
\hline Murine BM-DCs & Sequential & OVA & Indirect & Ex vivo
\end{tabular}

Murine BM-DCs

$$
\text { centrifugation }
$$

Human monocytederived DCs

Sequential centrifugation

Murine BM-DCs

Human monocytederived DCs

Murine BM-DC
MAGE.A1 and MAGE3.DP04 (human EVs)
Sequential centrifugation

a-galactosylceramide (aGC),

OVA

Indirect OVA
OVA-Exosomes and OVA-MVs were equally enriched in immunostimulatory molecules (MHC I, MHC II, CD40, CD80, CD86, CD54). OVA-Exosomes were more potent to induce OVA-specific immune response.

OVA-Exosomes carried high levels of OVA, MVs contained barely detectable OVA. OVA-Exosomes or OVA-Exosomes+OVA-MVs induced OVA-specific CD8 ${ }^{+} \mathrm{T}$ cells whereas OVA-MVs did not activated OVA-specific CTLS.

OVA-Exosomes were more efficient in eliciting OVA-specific IgG production.

\section{Ex vivo}

Large EVs (IEVs) and small EVs (sEVs) induced $\mathrm{CD} 4^{+} \mathrm{T}$ cell activation with equal efficiency. IEVs and sEVs isolated from immature DCs were different in their capacity to orient Th response: IEVs induced secretion of Th2 cytokines (IL-4, IL-5, IL-13), sEVs - Th1 cytokines (IFN- $\gamma$ ).

EVs transmembrane receptors involved in T cell regulation - IEVs - CD80, sEVs - CD40 and DC-SIGN.

IEVs and sEVs isolated from mature DCs functional differences were abolished, both types of EVs induced IFN- $\gamma$ synthesis.

(aGC+OVA)-EVs induced strong innate and OVA-specific adaptive immune response. ( $a \mathrm{GC}+\mathrm{OVA})-\mathrm{EV}$ s were induced $\gamma \delta \mathrm{T}$ celldependent, iNKT cell-mediated and OVAspecific $T$ and $B$ cell mediated immunity.

\section{In vivo B16-OVA melanoma model}

Therapeutic vaccination (IV) of mice with $(\alpha G C+O V A)-E V s$ resulted in:

$\downarrow$ tumour growth

$\uparrow$ tumour infiltration with antigen-specific CD8+

T cells,

$\downarrow$ median survival

In comparison with melanoma-bearing mice

immunized with soluble $a G C$ and OVA.

Boosting vaccination with ( $\mathrm{aGC}+\mathrm{OVA})$-EVs further $\uparrow$ effects of treatment.

Indirect

Direct
Mouse EVs promoted IL15Ra-dependent proliferation and NKG2D-dependent activation of NK cells in vivo.

Human EVs carried functional IL-15R $a$ and transpresented IL-15 to NK with activating proliferation of $\mathrm{NK}$ and production of IFN- $\gamma$ in vitro.

Human EVs carried NKG2D ligands (ULBP-1, $\mathrm{MICA} / \mathrm{B})$ that promoted activation of NK cells.
Tkach et al., 2017

Gehrmann et al., 2013

Viaud et al., 2009 
TABLE 2 | Continued

B. Vaccines on the base of DC-derived EVs.

\begin{tabular}{|c|c|c|c|c|c|}
\hline EV origin & $\begin{array}{l}\text { Isolation } \\
\text { method }\end{array}$ & $\begin{array}{l}\text { Carried/loaded } \\
\text { molecules }\end{array}$ & $\begin{array}{l}\text { Strategy of } \\
\text { loading }\end{array}$ & Biological effects & Reference \\
\hline Murine BM-DCs & $\begin{array}{l}\text { Sequential } \\
\text { centrifugation }\end{array}$ & TNF, FasL, TRAIL & & $\begin{array}{l}\text { Ex vivo } \\
\text { EVs directly triggered caspase activation and } \\
\text { apoptosis in tumour cells: } \\
\text { EVs cytotoxicity against B16 melanoma } \\
\text { (maximal at } 48 \text { h): } \\
\text { EVs from immature DCs (iEVs) - 10-30\% of } \\
\text { specific lysis. } \\
\text { EVs from mature DCs (mEVs) - 20-60\% of } \\
\text { specific lysis. } \\
\text { mEVs cytotoxicity against KLN205 lung } \\
\text { squamous carcinoma - 3-35\% of specific lysis. } \\
\text { mEVs cytotoxicity against MC38 colon } \\
\text { adenocarcinoma - 10-22\% of specific lysis. } \\
\text { EVs activated NK cells and stimulated } \\
\text { them to secrete IFN- } \gamma \text { upon the interaction } \\
\text { of transmembrane TNF on EVs with TNF } \\
\text { receptors on the surface of NK cells. }\end{array}$ & Munich et al., 2012 \\
\hline Murine BM-DCs & $\begin{array}{l}\text { Sequential } \\
\text { centrifugation }\end{array}$ & $\begin{array}{l}\text { TLR-ligands: } \\
\text { LPS (TLR4 ligand) } \\
\text { Pam }{ }_{3} \text { synthetic } \\
\text { (TLR1/2 ligand) }\end{array}$ & Direct & $\begin{array}{l}\text { Model 1. Incubation of LPS-iEVs or LPS- } \\
\text { mEVs with DCs and aNK cells in vitro } \\
\text { (1) LPS-EVs activated bystander DCs by } \uparrow \\
\text { expression of transmembrane TNF (tmTNF) } \\
\text { and soluble TNF. } \\
\text { (2) enhanced iDCs/aNK crosstalk - interaction } \\
\text { between tmTNF-DCs with TNFR2-aNK } \\
\text { resulted in } \uparrow \text { IFN- } \gamma \text { by aNK. }\end{array}$ & $\begin{array}{l}\text { Sobo-Vujanovic } \\
\text { et al., } 2014\end{array}$ \\
\hline
\end{tabular}

Model 2. Incubation of $\mathrm{Pam}_{3}-\mathrm{mEVs}$ with splenocytes in vitro

$\mathrm{Pam}_{3}-\mathrm{mEV}$ s $\uparrow \mathrm{iDCs} / \mathrm{NK}$ crosstalk ( $\uparrow$ secretion of IFN- $\gamma$ by $\mathrm{NK}$ ).

Murine BM-DCs matured with either poly $(\mathrm{l}: \mathrm{C})$ (TLR-3L), LPS (TLR-4L) or CpG-B (TLR-9L)
Sequential centrifugation
OVA

Antigens from $\mathrm{HOCl}$ oxidized necrotic B16-F10 cells
Indirect

Poly(l:C) is particularly favorable TLR agonist for DC maturation during antigen loading and EVs production for cancer immunotherapy.

\section{In vivo OT-I adoptive transfer model}

Poly(l:C)-OVA-EVs (IV or ID injected in mice) stimulated proliferation of OVA-specific $\mathrm{CD} 8^{+}$and CD4+ T cells, activated Th1 immune response.

\footnotetext{
In vivo B16-F10 melanoma model

Therapeutic settings

Vaccines (ID injected in mice):

Poly(I:C)-B16-EVs

LPS-B16-EVs

CpG-B-B16-EVs

All EVs formulations were able to $\downarrow$ growth of

B16-F10 tumours.

Poly(I:C)-B16-EVs were the most efficient

- induced robust activation of melanomaspecific $C D 8^{+} \mathrm{T}$ cells in tumour-draining lymph nodes, spleen and tumour mass; activated recruitment of NK and NK-T cells to the tumour site; significantly $\downarrow$ tumour growth and $\uparrow$ survival of diseased animals.
} 
TABLE 2 | Continued

B. Vaccines on the base of DC-derived EVs.

\begin{tabular}{|c|c|c|c|c|c|}
\hline EV origin & $\begin{array}{l}\text { Isolation } \\
\text { method }\end{array}$ & $\begin{array}{l}\text { Carried/loaded } \\
\text { molecules }\end{array}$ & $\begin{array}{l}\text { Strategy of } \\
\text { loading }\end{array}$ & Biological effects & Reference \\
\hline \multirow[t]{6}{*}{ Murine spleen DCs } & $\begin{array}{l}\text { Total exosome } \\
\text { isolation kit } \\
\text { (Invitrogen) }\end{array}$ & & & $\begin{array}{l}\text { Heat stressed and high } \mathrm{CO}_{2} \text {-treated EVs } \\
\left(\mathrm{HS}-\mathrm{CO}_{2}-\mathrm{EVs}\right) \text {. }\end{array}$ & Wang et al., 2015 \\
\hline & & & & Ex vivo & \\
\hline & & & & $\begin{array}{l}\mathrm{HS}-\mathrm{CO}_{2} \text {-EVs inhibited AGS gastric cancer cell } \\
\text { prolipheration ( } 55 \% \text { inhibition), induced tumour } \\
\text { apoptosis ( } 28 \% \text { tumour apoptotic cells). }\end{array}$ & \\
\hline & & & & $\begin{array}{l}\text { In vivo AGS human gastric cancer } \\
\text { xenograft model }\end{array}$ & \\
\hline & & & & $\mathrm{HS}-\mathrm{CO}_{2}-\mathrm{EVs}$ inhibited AGS tumour growth in & \\
\hline & & & & $\begin{array}{l}1.54 \text { times as compared with control group in } \\
\text { nude mice. }\end{array}$ & \\
\hline
\end{tabular}

\section{EVs-based anti-tumour immunotherapy in clinical trials.}

\begin{tabular}{|c|c|c|c|c|c|c|}
\hline Tumour type & Phase & $\begin{array}{l}\text { Number } \\
\text { of } \\
\text { patients }\end{array}$ & $\begin{array}{l}\text { EV origin; } \\
\text { isolation method }\end{array}$ & $\begin{array}{l}\text { Carried/loaded } \\
\text { molecules }\end{array}$ & Outcome & References \\
\hline $\begin{array}{l}\text { Melanoma IIIB/IV } \\
\text { stage }\end{array}$ & Phase 1 & 15 & $\begin{array}{l}\text { Monocyte-derived } \\
\text { DCs; } \\
\text { Ultrafiltration, } \\
\text { sucrose } \\
\text { ultracentrifugation }\end{array}$ & MAGE3 peptides & $\begin{array}{l}\text { There was no grade II toxicity } \rightarrow \\
\text { maximal tolerated dose was not } \\
\text { achieved. } \\
\text { Immunological results } \\
\text { MAGE3-specific CD4+ and CD8+ }{ }^{+} \text {cell } \\
\text { responses were not detected. } \\
\text { Clinical results } \\
\text { 1/15 - partial response (according to } \\
\text { RECIST criteria). } \\
\text { In skin and lymph nodes: } \\
\text { 1/15 - minor response. } \\
2 / 15 \text { - stable response. } \\
\text { 1/15 - mixed response. }\end{array}$ & Escudier et al., 2005 \\
\hline
\end{tabular}


TABLE 2 | Continued

C. EVs-based anti-tumour immunotherapy in clinical trials.

\begin{tabular}{|c|c|c|c|c|c|c|}
\hline Tumour type & Phase & $\begin{array}{l}\text { Number } \\
\text { of } \\
\text { patients }\end{array}$ & $\begin{array}{l}\text { EV origin; } \\
\text { isolation method }\end{array}$ & $\begin{array}{l}\text { Carried/loaded } \\
\text { molecules }\end{array}$ & Outcome & References \\
\hline $\begin{array}{l}\text { Advanced } \\
\text { melanoma }\end{array}$ & Phase 1 & 15 & $\begin{array}{l}\text { Monocyte-derived } \\
\text { DCs; } \\
\text { Ultrafiltration / } \\
\text { diafiltration, Sucrose } \\
/ \mathrm{D}_{2} \mathrm{O} \text { cushion } \\
\text { ultracentrifugation }\end{array}$ & $\begin{array}{l}\text { MAGE.A1 and } \\
\text { MAGE3.DP04 }\end{array}$ & $\begin{array}{l}\text { Immunological results } \\
7 / 14 \text { - restored the number and } \\
\text { NKG2D-dependent function of NK cells }\end{array}$ & Viaud et al., 2009 \\
\hline $\begin{array}{l}\text { Non-small cell lung } \\
\text { cancer }\end{array}$ & Phase 1 & 9 & $\begin{array}{l}\text { Monocyte-derived } \\
\text { DCs; }\end{array}$ & MAGE peptides & $\begin{array}{l}\text { Immunological results } \\
\text { No major toxicity. } \\
3 / 9 \text { - MAGE-specific T cell } \\
\text { responses; } \\
2 / 9 \text { - } \uparrow \text { increased NK cell lysis }\end{array}$ & Morse et al., 2005 \\
\hline
\end{tabular}

aNK, activated NK (splenocytes activated with IL-2 for 6 days); CRCL, chaperone-rich cell lysate; CTLs, cytotoxic T-lymphocytes; DCs, dendritic cells; EVs, extracellular vesicles; GM-CSF, granulocyte-macrophage colony-stimulating factor; HS, heat stressed; ID, intradermal; iDCs, immature DCs; iEVs, extracellular vesicles from immature DCs; IFN, interferon; IL, interleukin; IT, intratumoural; IEVs, large extracellular vesicles; LPS, lipopolysaccharide; mEVs, extracellular vesicles from mature DCs; MVs, microvesicles; NK, natural killer; OVA, ovalbumin; PBMC, peripheral blood mononuclear cells; PT, peritumoural; SC, subcutaneous; sEVs, small extracellular vesicles; TGF, transforming growth factor; Th, T-helper cells; tmTNF, transmembrane tumour necrosis factor; TNF, tumour necrosis factor; Tregs, T-regulatory cells.

Other methods of EV isolation, such as immunoaffinity capturebased and microfluidics-based isolation techniques, are more expensive and technically complicated, and in practice are not used for the isolation of DC-derived or DC-targeted MVs. Therefore, these approaches are not considered in the present review. The principles of the different EV isolation techniques are described in detail in other reviews (Li et al., 2017; Pariset et al., 2017).

\section{METHODS OF EV LOADING WITH THERAPEUTIC MOLECULES}

For proper activation of an anti-tumor immune response, the antigen-presenting cells (APC), in particular DCs, should convey three signals to T cells: (1) presentation of tumor antigens in complexes with MHC class I and II molecules on the surface of DCs to T-cell receptors (2) signal transmission via interaction of co-stimulatory and adhesion molecules expressed on the surface of DCs to their receptors on T cells; and (3) production of T-cell stimulatory cytokines by DCs (Kapsenberg, 2003).

It is known that DC-derived EVs carry all the molecules required to activate anti-tumor $\mathrm{T}$ cell-mediated immune responses (Seo et al., 2018). On their surface, DC-derived EVs contain functionally active complexes containing tumor antigens and MHC molecules class I and II, as well as co-stimulatory and adhesion molecules (Morelli et al., 2004; Chaput et al., 2006). Furthermore, it has been shown that EVs are able of carrying cytokines (Gulinelli et al., 2012). Therefore, DC-derived EVs are assumed to interact with $\mathrm{T}$ lymphocytes and directly trigger anti-tumor immune responses that has been proven by many experimental data (Wang et al., 2013; Lu et al., 2017; Chen et al., 2018 etc.) (see Table 2B).

With respect to tumor cell-derived DC-targeted EVs, these vesicles may transfer tumor antigenic peptides and immunostimulatory molecules to DCs, resulting in the induction of DCs exhibiting high immunogenicity (Pitt et al., 2014).

Generally, for proper activation of immune responses, in addition to tumor-associated antigens and immunostimulatory molecules, DC-derived and DC-targeted EVs should carry tumor-targeted molecules. EVs can also carry therapeutic NAs, such as small non-coding regulatory RNA (siRNA, miRNA) for the targeting of certain genes in recipient cells, thus enhancing immunogenicity or inhibiting negative signals (Jiang et al., 2017). The efficient loading of EVs with therapeutic molecules is the most important step in the preparation of EV-based antitumor vaccines. Therapeutic molecules can be delivered to EVs indirectly by the loading of EV-secreting cells followed by the isolation of EVs or directly by the loading of preliminarily isolated EVs (Batrakova and Kim, 2015). Summarizing the investigations performed over recent decades, in the next part of the present review we will discuss the molecules used for the loading of antitumor EVs and provide an overview of the methods used for the indirect or direct loading of EVs with therapeutic molecules.

\section{Loading of EVs With NAs}

NA-based therapeutics is a promising tool for the modification of immune cell properties and treatment of a variety of human diseases. Plasmid DNA and mRNA encoding tumor antigens, immunostimulatory molecules, EV-targeted proteins, and regulatory short non-coding RNA (miRNA, siRNA), can be successfully used to launch or enhance the anti-tumor potential of EV-based vaccines (Van den Boorn et al., 2013). The main problems with NA application are instability of the naked NA in the presence of nucleases as well as non-targeted delivery. As a result, various types of chemical modifications of NAs and nanocarriers have been developed to ensure the stability of NAs and to provide their targeted delivery to both cells and EVs. 
Overall, only two strategies are used to load EVs with NAs: (1) indirect loading - preliminary transfection/transduction/ electroporation of EV-secreting cells with NA followed by EVs isolation or (2) direct loading of preliminarily isolated EVs with the NA (Johnsen et al., 2014).

\section{Indirect Loading of EVs With NA}

Indirect loading of EVs is achieved by preliminary delivery of NA to EV-secreting cells by transfection, transduction, or electroporation. Subsequently, NA may be sorted into MVBs and secreted by exosomes (in the case of regulatory small noncoding RNA, such as siRNA or miRNA) or NA can be translated to peptides or proteins (tumor peptides, chimeric proteins, targeting molecules) that can be carried by EV to immune or tumor cells.

This approach has been well adapted for miRNA and siRNA loading. Overexpression of miRNA in EV-secreting cells is typically realized by transfection of cells with plasmid DNA or viral vectors encoding miRNA (Katakowski et al., 2013; Wang et al., 2016), while siRNA, in addition to the above-mentioned methods, can be delivered to cells in the form of siRNA duplexes. Recent reports have revealed that the use of siRNA duplexes is preferred (Zhang et al., 2014b) and allows packaging of approximately 0.001 to 0.14 pmol siRNA into 1 g EVs (Zhang et al., 2014b; Liu et al., 2015). It was revealed that indirect loading of murine leukemia-derived EVs with TGF- $\beta 1$ shRNA resulted in robust maturation of DCs, activation Th1 immune response and pronounced inhibition of tumor growth in vivo (Huang et al., 2017).

The loading of high-molecular weight NAs, such as plasmid DNA and mRNA, into EVs is associated with additional difficulties, such as low loading efficiency due to the size of NAs and the possibility of losing functional activity of NAs. Thus, in the case of high-molecular weight NAs, the common strategy for the modification of EVs is preliminary transfection/ transduction/electroporation of EV-secreted cells.

Using the indirect NA delivery technique, DC-derived or tumor-derived DC-targeted EVs can be modified with different proteins, such as tumor-associated antigens or DC-activating molecules, respectively, by preliminary transfection/transduction of EV-producing cells with plasmid DNA/RNA/viral vectors encoding these proteins. Concerning the modification of DC-derived EVs with tumor antigens, DCs can be transduced with viral vectors encoding full-length tumor-associated proteins (Wang et al., 2013; Lu et al., 2017) or transfected with tumor RNA encoding a pool of tumor-associated proteins and peptides (Gehrmann et al., 2013). Following transfection/transduction of cells, intracellular processing of proteins occurs, and complexes of tumor peptides with MHC molecules class I and II are formed and exposed on the surface of EVs. Such DC-derived EVs carrying tumor-associated peptides in complex with MHC molecules are able to directly activate highly efficient T-cell antitumor immune responses both in vitro and in vivo (Gehrmann et al., 2013; Wang et al., 2013; Lu et al., 2017).

To place a particular peptide or protein on the surface of EVs, indirect loading of EV-producing cells with NA encoding chimeric proteins consisted of EV surface protein (lactadherin,
Lamp2b, etc.) fused with protein or another molecule of interest (tumor antigen, immunostimulatory molecules as well as DC- or tumor-targeted molecules) can be applied.

For example, lactadherin, exosome-specific anchor expressed on the surface of EVs, can be used to modify EVs. EV-secreting murine melanoma cells were transfected with plasmid DNA encoding lactadherin fused to streptavidin; the EVs produced by these cells were shown to express streptavidin on their surface and could be modified with either biotinylated CpG DNA (Morishita et al., 2016) or GALA peptide (Morishita et al., 2017) for activation of DC maturation or enhancement of EV cargo release into the cytosol of recipient cells, respectively. Moreover, lactadherin was also fused to the tumor-associated antigens, CEA and HER2, to modify EVs produced by HER2 ${ }^{+}$breast carcinoma cells. Adenoviral vectors encoding lactadherin-CEA or lactadherin-HER2 fusion proteins were used to transduce EV-secreting cells. Enhanced expression of tumor antigens on the surface of EVs resulted in significant activation of antigenspecific anti-tumor immune responses in animal models of breast tumors (Hartman et al., 2011).

A mutant form of the HIV-1 Net protein ( $\mathrm{Net}^{\text {mut}}$ ), that has been shown to have extraordinarily high levels of accumulation in exosomes (Lattanzi and Federico, 2012), can be used as anchors to modify EVs. Plasmid DNA encoding $\mathrm{Net}^{\text {mut }}$ fused to the tumor antigens, HER2 or MART-1, was employed to indirectly modify human muscle cell-derived EVs. Modified EVs were demonstrated to possess great anti-tumor potential against breast cancer and lymphoblastoma in vitro and in vivo (Anticoli et al., 2018).

EVs possess the natural property of transferring their contents to target cells and tissues; however, in their unmodified form, EVs are known to accumulate mainly in the liver, kidneys, intestine, lungs, and spleen of laboratory animals (Wiklander et al., 2015). Accordingly, many studies have been conducted with the aim of targeting EV/NA complexes to organs and tissues of interest (Alvarez-Erviti et al., 2011; Tian et al., 2014; Liu et al., 2015; Bellavia et al., 2017). Modification of EVs with DC- or tumor cell-targeted molecules can allow an increase in the delivery efficiency of miRNA and siRNA to DCs or tumor cells and enhance the biological effect of therapeutic NA. This approach can be performed by transfection or transduction of EV-secreting cells with plasmid DNA or viral vectors, respectively, encoding EV surface proteins fused to DC-/tumortargeted or immunostimulatory molecules.

For instance, it has been demonstrated that the Lamp2b protein expressed on the surface of EVs can be modified by fusion with the RVG-peptide (neuron-specific rabies viral glycoprotein that binds to acetylcholine receptors) to target DC-derived EVs to neuronal cells in vitro and to brain cells in vivo (Alvarez-Erviti et al., 2011; Liu et al., 2015). Application of $\alpha$-bungarotoxin (inhibitor of acetylcholine receptors) has been shown to result in the loss of function of RVG-EVs with respect to the ability to transfer BACE1 siRNA to Neuro2A cells (Alvarez-Erviti et al., 2011). In another study, DC-derived EVs were modified with Lamp2b by fusion with the iRGD peptide targeted to av-integrin-positive breast cancer cells. It was demonstrated that these iRGD-modified EVs more effectively penetrated into MDA-MB-231 cells than unmodified 
EVs. Moreover, intravenous injection of iRGD-EVs into tumorbearing mice has been reported to result in the rapid accumulation of reprogrammed EVs in tumors (Tian et al., 2014).

Modification of DC-targeted tumor-derived EVs involves preliminary transfection of EV-producing cells with plasmid DNA encoding DC-targeted/-activating molecules, for example CD40L (Wang et al., 2014). It was shown that EVs derived from CD40L-modified Lewis lung carcinoma cells were highly immunogenic towards DCs in vitro and extremely efficient in a protective and therapeutic scheme of treatment for murine lung carcinoma in vivo (Wang et al., 2014).

It appears that reprogrammed EVs have a similar transfection efficiency to commercial transfection reagents. It has been reported that RVG-EVs have a transfection efficiency comparable with commercial TransIT LT1 transfection reagent (Mirus Bio). In this work, DC-derived RVG-modified EVs transferred three types of $\alpha$-Syn siRNA to a human SH-SY5Y neuroblastoma cell line expressing mouse $a$-Syn-HA. The level of $a$-Syn mRNA/ protein reduction was similar, with a slight advantage for RVGEVs over TransIT LT1-mediated delivery (Cooper et al., 2014). Moreover, a similar result has been demonstrated previously with RVG-modified murine DC-derived EVs (Alvarez-Erviti et al., 2011). The delivery of GAPDH and cyclophilin B siRNA was performed by reprogrammed RVG-EVs, and the level of gene silencing was comparable with that obtained following transfection with Lipofectamine 2000 (Thermo Fisher Scientific) transfection reagent (Alvarez-Erviti et al., 2011).

\section{Direct Loading of EVs With NA}

In addition to the indirect modification of EVs by preliminary cell transfection, another approach is the direct modification of EVs with DC-/tumor-targeted molecules.

Electroporation is often used for direct loading of EVs with low-molecular weight NAs, with an efficiency of approximately $3 \%$ to $24 \%$ transfected EVs (Alvarez-Erviti et al., 2011; Wang et al., 2017; Usman et al., 2018). This technique has been applied to EVs of different origins including DCs (Alvarez-Erviti et al., 2011; Wang et al., 2017). Electroporation is best suited to the direct loading of EVs with small non-coding regulatory RNAs and antisense nucleotides (ASOs). For instance, miRNA-155 was efficiently directly loaded into EVs derived from murine colon carcinoma cells by using electroporation (Asadirad et al., 2019). miRNA-155-EVs was shown to significantly enhance maturation of DCs and stimulate their immunostimulatory functions (Asadirad et al., 2019). One of the main problems with electroporation is the aggregation of EVs, which result in distortion of the true efficiency of NA incorporation into EVs (Kooijmans et al., 2013; Usman et al., 2018).

In addition, small non-coding RNA can be directly delivered to EVs in the form of conjugates with hydrophobic molecules, such as cholesterol. This approach is prospective, since it allows loading of a large number of NA molecules into EVs in the absence of any transfection reagents and additional manipulations (Didiot et al., 2016). Nevertheless, the functional activity of cholesterolconjugated siRNA can be lost in recipient cells (Stremersch et al., 2016). Indeed, melanoma B16 or monocyte/DC-derived EVs loaded with cholesterol-conjugated siRNA (chol-siRNA) were used to silence CD45 and eGFP genes in JAWSII monocytes and H1299 non-small cell lung carcinoma cells, respectively. Highly efficient loading of EVs with chol-siRNA was shown; specifically, $15 \mu \mathrm{g}$ EVs $\left(\sim 6.6 \times 10^{10}\right.$ vesicles $)$ were able to bind $80 \%$ of the 10 pmol chol-siRNA, corresponding to approximately 73 cholsiRNA molecules per vesicle (Stremersch et al., 2016). EVs loaded with chol-siRNA were demonstrated to efficiently penetrate the target cells; however, no downregulation of gene expression in either tested cell line was observed (Stremersch et al., 2016). In another study, it was reported that approximately $74 \%$ of cholsiRNA was loaded into Neuro2A- or DC-derived EVs by using electroporation, and subsequently recommended to use roughly 15 molecules of chol-siRNA per vesicle to achieve this efficiency. In this case, EVs loaded with chol-siRNA were able to transport functionally active siRNA to target cells and downregulate target genes in a concentration-dependent manner (O'Loughlin et al., 2017). The loss of functional activity of chol-siRNA delivered by EVs observed in the Stremersch's investigation was possibly associated with high affinity between EVs and chol-siRNA, and hence, inability to release siRNA into the cytosol for biological action to occur. Furthermore, the structure and length of the linker between siRNA and cholesterol molecules are of great importance to ensure the biological activity of chol-siRNA conjugates (Petrova et al., 2012).

A technique for direct targeting EVs to tumor cells is the labeling of EVs with aptamers. This technique can be conveniently used for artificial EV-mimics derived from cell membranes. For example, the tumor-targeted anti-nucleolin aptamer, AS1411, conjugated to cholesterol-poly(ethylene glycol) was used to modify the membrane of murine DCs, which were further processed by extrusion to generate artificial mimics of natural EVs that significantly eradicated tumors in MDA-MB-231 breast tumor xenograft model (Wan et al., 2018). In another study, murine DC-derived EVs were also modified by AS1411. The binding efficiency of AS1411-modified EVs to breast cancer cells was roughly fourfold greater in comparison with unmodified EVs (Wang et al., 2017). Intravenous injection of miR-let-7-loaded AS1411-modified EVs or control EVs to breast tumor-bearing mice resulted in much higher intratumoral accumulation of the AS1411-modified EVs in comparison with unmodified EVs that resulted in more significant retardation of MDA-MB-231 tumor growth (Wang et al., 2017).

At the end of this section, we briefly consider some other techniques for NA loading into EVs that were recently used to prepare anti-tumor EVs. In some studies, transfection reagents, for example Lipofectamine 2000 (Thermo Fisher Scientific), were used for the direct loading of EVs with NA (Wahlgren et al., 2012; Shtam et al., 2013; George et al., 2018). The main problems of using chemical transfectants to directly load EVs are formation of surface conglomerates of NA/transfectant complexes with EVs that can drastically alter the original vesicle composition (Wahlgren et al., 2012). In other studies, $\mathrm{CaCl}_{2}$ associated transfection of isolated EVs combined with heat shock at $42^{\circ} \mathrm{C}$ has been reported (Zhang et al., 2017; Zhang et al., 2018). This approach allows the loading of approximately 200 copies of siRNA per EV. Sonication has also been used for NA loading into EVs, showing a significant decrease in siRNA aggregation 
in comparison with electroporation (Lamichhane et al., 2016). Moreover, the promising approach of using freezing/thawing and extrusion methods, in addition to a permeabilization technique with saponin, has been demonstrated for the efficient loading of EVs (Haney et al., 2015).

\section{Direct and Indirect Modification of EVs With Proteins and Peptides}

To use EVs as immunotherapeutic cell-free vaccines, DC-derived EVs can be modified not only with NAs but also with tumorassociated proteins or peptides. Similar to NA delivery into EVs, there are two techniques for loading EVs with proteins/peptides: indirect loading of EV-secreting cells and direct loading of EVs.

This technique allows to prepare EVs that are able to activate tumor antigen-specific immune responses. Both indirect and direct loading of EVs with proteins/peptides leads to the presentation of tumor-associated peptides in complexes with MHC class I and II molecules on DC-derived EVs and promotes the interaction of these EVs with T-lymphocytes or NK cells and subsequent activation of anti-tumor immunity.

Indirect loading of DC-derived EVs was demonstrated with the tumor-specific proteins or peptides MAGE3 (Viaud et al., 2009) and HPV early antigen 7 (Chen et al., 2018), model tumor antigens, such as OVA and OVA-derived peptide SIINFEKL (Gehrmann et al., 2013; Naslund et al., 2013; Yao et al., 2013; Damo et al., 2015; Wahlund et al., 2017), tumor lysates (Guan et al., 2014; Bu et al., 2015), and even HOCl-oxidized B16 melanoma cells containing both proteins and NAs (Damo et al., 2015). Immature DCs possess the intrinsic ability to capture proteins and peptides from surrounding fluids and tissues; therefore, there is no need to use special reagents or techniques for loading (Savina and Amigorena, 2007). Captured proteins and peptides are processed and tumor antigens in complex with MHC class I and II molecules are subsequently exposed on the surface of DCs, and as a consequence, on DC-derived EVs (Pitt et al., 2014; Markov et al., 2016). The presence of tumor peptides on the surface of EVs is proven in most cases by pentamer staining, ELISA, or western blotting assays. It should be mentioned that the maturation status of DCs loaded with proteins/peptides is essential for expression of costimulatory and adhesion molecules on the surface of DC-derived EVs, which are needed for the induction of an efficient anti-tumor immune response (Lutz and Schuler, 2002). Hence, the choice of suitable maturation stimuli for the treatment of DCs is of great importance. Different compounds have been used to stimulate the maturation of DCs, such as LPS, poly(I:C), CpG-oligonucleotide, and TNF- $\alpha$. It has been shown that mature DC-derived EVs indirectly loaded with tumor antigens activate efficient anti-tumor immune responses in vitro and in vivo (Naslund et al., 2013; Bu et al., 2015; Damo et al., 2015; Wahlund et al., 2017; Chen et al., 2018) (see DC-Derived EVs and Table 2B).

The technique of direct loading of EVs with tumor antigenic peptides was developed by $\mathrm{Hsu}$ and co-authors (Hsu et al., 2003). Direct binding of peptides to MHC I and II molecules on the surface of DC-derived EVs was performed under mildly acidic loading conditions. It was demonstrated that MHC class
I molecules on EVs can be directly loaded with peptides, such as HLA-A2-restricted MART1 tumor peptide, at much greater levels than indirect loading, requiring a 100- to 1000-fold lower peptide concentration. Moreover, it was demonstrated that MHC I molecules efficiently bind tumor peptides at $\mathrm{pH} 4.2$ in the presence of $\beta_{2}$-microglobulin $\left(\beta_{2} \mathrm{~m}\right)$; in the absence of $\beta_{2} \mathrm{~m}$, MHC I molecules also efficiently bind tumor peptides under less acidic conditions ( $\mathrm{pH}$ 5.2). Although the efficiency of peptide binding at $\mathrm{pH} 5.2$ in the absence of $\beta_{2} \mathrm{~m}$ is approximately $50 \%$ of that observed at $\mathrm{pH} 4.2$ in the presence of $\beta_{2} \mathrm{~m}$, the biological activity of DC-derived EVs prepared in accordance with both methods is comparable (Hsu et al., 2003). MHC II molecules that are expressed in high density on the surface of DC-derived EVs also efficiently bind tumor peptides under the same conditions. Obtained complexes of MHC I or MHC II with tumor peptides maintain complete functional activity; thus, the technique of direct loading of DC-derived EVs with peptides consists not of peptide delivery inside EVs but the binding of peptides with MHC class I and II molecules on the surface of EVs. In this form, EVs can stimulate both $\mathrm{CD}^{+}$cytotoxic T-lymphocytes and CD $4^{+}$ T-helper cells, which are crucial for triggering an efficient antitumor immune response (Hsu et al., 2003). More recently, this technique was used to load DC-derived EVs with the tumorassociated MAGE3 peptide to treat advanced melanoma in clinical trial (Viaud et al., 2009). Vaccination of patients with obtained EVs resulted in activation of NK cells (Viaud et al., 2009).

\section{ANTI-TUMOR POTENTIAL OF DC-DERIVED AND DC-TARGETED EVS IN VITRO AND IN VIVO}

\section{Tumor Cell-Derived DC-Targeted EVs}

The anti-tumor potential of DC vaccines primarily depends on the efficiency of DC loading with tumor antigens. Tumor-derived EVs are known to be natural transport vectors that carry a large variety of tumor antigens, and thus can serve as vesicles for the direct delivery of tumor antigens to DCs. Current success in application of tumor-derived DC-targeted EVs to treat tumors in different murine models in vivo is summarized in Table 2A.

The ability of tumor cell-derived EVs to induce an anti-tumor immune response depending on their size has been investigated, and large-sized tumor cell-derived EVs (MVs, diameter 100-1000 nm) were shown to be more immunogenic than small-sized EVs (exosomes, diameter 60-100 nm). Treatment of tumor-bearing mice with large- and small-sized EVs resulted in the inhibition of tumor growth, with $50 \%$ and $12.5 \%$ of mice, respectively, remaining tumor-free. Furthermore, treatment of mice with tumor cell-derived large-sized EVs resulted in the activation of anti-tumor cytotoxic T-lymphocytes (CTLs) that were 1.5 -fold to 2 -fold more efficient in comparison with CTLs activated by treatment with small-sized EVs (Zhang et al., 2014a). It should be mentioned that despite the successful application of cell-free vaccines based on DC-targeted tumorderived EVs, DCs pre-loaded with tumor-derived EVs inhibited tumor growth significantly more efficiently in comparison with EV-based vaccines in all tested tumor models (Zhang et al., 
2014a). This can be explained by the fact that tumor-derived EVs are not specifically targeted to DCs, and following subcutaneous inoculation in mice, interact with cells of different origins, not only with DCs, thus losing their antitumor potential.

Indeed, it was revealed that DCs loaded with EVs produced by murine L1210 leukemia cells activate a more efficient anti-tumor immune response in both prophylactic and therapeutic regimens in comparison with cell-free EV-based vaccines. In a model of L1210 murine leukemia, it was shown that subcutaneous injection of DC/L1210-EVs at a dose of $4 \times 10^{6}$ cells per mouse results in complete eradication of tumors in a therapeutic setting and protection of all mice in a prophylactic setting, whereas vaccines based on tumor-derived EVs are not as efficient (Yao et al., 2014).

The next question is whether DCs loaded with tumor-derived EVs are more immunogenic than classic DC-based vaccines loaded with tumor proteins or NA encoding tumor antigens. On the basis of the facts that tumor vesicles contain large amounts of different tumor antigens (Wolfers et al., 2001) and have a natural ability to efficiently deliver cargo to the cells (Ha et al., 2016), it appears that the use of tumor-derived EVs as a source of tumor antigens to load DCs is superior to commonly used sources of tumor antigens (tumor proteins, peptides, or NAs). Indeed, it has been shown that human DCs loaded with glioma cell-derived EVs activate anti-tumor CTLs ex vivo that kill glioma cells twofold more efficiently in comparison with CTLs primed with tumor lysate-pulsed DCs (Bu et al., 2011). Using a mouse AB1 malignant mesothelioma model, it was revealed that treatment of tumor-bearing mice with DCs loaded with either tumor cellderived EVs or tumor lysate results in infiltration of $\mathrm{CD} 4^{+} \mathrm{T}$ cells, CD8 ${ }^{+} \mathrm{T}$ cells, and DCs into tumor tissues. However, in the case of EV-loaded DCs, a higher increase in overall and median survival of experimental animals was observed as compared with lysate-pulsed DCs: the overall survival (on the $52^{\text {nd }}$ day of tumor development) was $0 \%, 16.7 \%$, and $33.3 \%$; and the median survival was $13,18.5$, and 29.5 days for mice treated with PBS, lysate-pulsed DCs, and EV-loaded DCs, respectively (Mahaweni et al., 2013). Greater immunogenicity of tumor cell-derived EV-loaded DCs has also been demonstrated. Treatment of WEHI3B myeloid leukemia-bearing mice with such EV-loaded DCs resulted in a more significant retardation of tumor growth and survival in animals as compared with treatment with lysatepulsed DCs (Gu et al., 2015). The efficiency of DC-based vaccines loaded with tumor cell-derived EVs was shown to be almost equal to that of protein-pulsed DCs. Thus, DCs loaded with EVs derived from B16-F10-OVA mouse melanoma cells were shown to activate anti-tumor and anti-metastatic immune responses in vivo with slightly less intensity than that evoked by OVA-loaded DCs: tumor occurrence was observed in one of eight mice and zero of eight mice, and the mean number of metastases was 5 and 0, respectively (Yao et al., 2013). Such high efficiency of proteinpulsed DCs is suggested to be associated with the model tumor antigen OVA, which is abundantly expressed in tumor cells and does not reflect the actual expression of tumor-associated antigens. When tumor-associated antigens were used to load DCs or DC-derived EVs, higher immunogenicity of EV-loaded DCs over oncoprotein-loaded DCs could be explained by prolonged presentation time and enhanced recovery of EVs in comparison with tumor proteins (Gu et al., 2015)

To enhance the immunogenicity of tumor-derived EVs, EV-secreting tumor cells or EVs themselves undergo modifications with different molecules or exposure to radiation. Tumor cell-derived EVs were shown to be indirectly (see Loading of EVs with NA) modified with the DC-targeted/-activating molecule CD40L (Wang et al., 2014), the Rab27a molecule that takes part in exosome secretion ( $\mathrm{Li}$ et al., 2013), the shRNA silencing immunosuppressive TGF- $\beta 1$ (Huang et al., 2017), or degraded cytosolic DNA (Diamond et al., 2018), as well as the $\mathrm{pH}$-sensitive GALA-peptide that contributes to the endosomal release of EVs into the cytosol of DCs (Morishita et al., 2017) or the immunostimulatory CpG DNA (Morishita et al., 2016). All modified tumor cell-derived EVs mentioned above showed high immunostimulatory activity that exceeded the activity of unmodified EVs. Thus, it was demonstrated that DC-targeted tumor cell-derived EVs can be successfully used for the loading of DCs, and as such, tumor EV-loaded DC vaccines had higher anti-tumor efficiency in comparison with classic DC vaccines.

Nevertheless, it should be mentioned that it is necessary to carefully test tumor-derived EVs during preparation of anti-tumor vaccines, since tumor-derived EVs despite immunotherapeutic potential possess immunosuppressive properties that can lead to inhibition of immune cell functions and as a result to escape of tumor from immunosurveillance and formation of metastatic niche. A short review of immunosuppressive action of tumor-derived EVs on immune cells is presented below.

\section{Immunosuppressive Action of Tumor Cell-Derived DC-Targeted EVs}

As indicated above, tumor-derived EVs were successfully applied as efficient source of tumor antigens to load DCs that eventually activated robust anti-tumor immune response in different murine tumor models (see Tumor Cell-Derived DC-Targeted EVs and Table 2). Nevertheless, immunotherapeutic potential of tumorderived EVs is confused and controversial. It was demonstrated that tumor-derived EVs along with immune stimulatory action could also deliver tolerogenic signals to immune cells (Whiteside, 2016b).

The immunoinhibitory effects of tumor-derived EVs on immune cells can be direct (when signals or cargo delivered by EVs inhibit the targeted cell functions) or indirect (when EVs reprogram the differentiation program of targeted cells, which then suppress functions of other cells) (Whiteside, 2016b). Indeed, on the one hand, tumor-derived EVs carry FasL and TRAIL molecules and can directly induce apoptosis of DCs (Peng et al., 2011; Ning et al., 2018) or effector CD4+ and CD8 ${ }^{+}$ T-lymphocytes (Whiteside, 2016a). On the other hand, tumorderived EVs can block differentiation of myeloid progenitor cells into $\mathrm{CD} 11^{+} \mathrm{DCs}$ and direct them to differentiate into myeloidderived suppressor cells (Xiang et al., 2009; Ning et al., 2018) or inhibit maturation and migration of DCs (Yang et al., 2011; Ning et al., 2018) that results in immunosuppression and favors tumor immune escape.

It was demonstrated that HSP72 and HSP105 expressed on the surface of tumor-derived EVs promoted DCs to produce high 
levels of pro-inflammatory cytokines (IL-6, PGE2, IL-1 $\beta$, TNF- $\alpha$ ) in a TLR2- and TLR-4-dependent manner (Shen et al., 2017). High levels of IL6 dramatically promoted tumor invasion and metastasis of murine melanoma by upregulation of transcription activity of STAT3 and production of STAT3-dependent MMP9 in tumor cells. It should be mentioned that depletion of IL-6 converted tumor-derived EVs from tumor promoters to inhibitors of tumor metastasis in vivo (Shen et al., 2017).

Human pancreatic cancer cell-derived EVs were shown to carry miR203 that inhibited expression of TLR4 and blocked secretion of IL-12 and TNF- $\alpha$ immunostimulatory cytokines in human DCs (Zhou et al., 2014).

Furthermore, tumor-derived EVs could drive differentiation and expansion of Treg cells (Huang et al., 2013; Whiteside, 2016a; Ning et al., 2018). Tumor cell-derived EVs induced the conversion of human conventional $\mathrm{CD} 44^{+} \mathrm{CD} 25^{-} \mathrm{T}$ cells to $\mathrm{CD} 4{ }^{+} \mathrm{CD} 25^{\text {hi }} \mathrm{FOXP}^{+}$Treg cells in a TGF- $\beta 1$-dependent manner (Wieckowski et al., 2009). Treg cells coincubated with tumor EVs were shown to upregulate the expression of FasL, TGF- $\beta$, IL-10, CTLA4, granzyme B, and perforin and exhibited enhanced suppressor functions (Szajnik et al., 2010).

NK cells being highly important in anti-tumor immunity due to induction an antigen-independent immune response against malignant cells (Fang et al., 2017) could be also inhibited by tumor cell-derived EVs (Whiteside, 2016b). It was demonstrated that NKG2D ligands (MICA, MICB, and ULBP) carried by tumor-derived EVs bound to the inhibitory receptor, NKG2D, on the surface of NK cells, with delivering of inhibitory signals and blocking of anti-tumor cytotoxicity of NK cells (Clayton et al., 2008; Lundholm et al., 2014). Another mechanism of tumor EV-mediated inhibition of NK functions was attributed to the presence of TGF- $\beta 1$ in EVs cargo, a cytokine suppressing cytotoxicity of NK cells (Szczepanski et al., 2011).

It can be assumed that the choice of the immunostimulatory or immunosuppressive effects of the tumor cell-derived EVs depends on many factors: isolation methods of EVs from tumor cells, DC loading conditions, used immunostimulating molecules, the stage of the tumor process, and so on. In any case, preparation of antitumor vaccines on the basis of tumor cell-derived EVs should be associated with comprehensive and thorough investigation of their all biologic effects on immune system. On the other hand, the immunosuppressive properties of the tumor cell-derived EVs can be successfully applied to treat autoimmune diseases or to reduce graft-tohost immune reactions.

\section{DC-Derived EVs}

DC-derived EVs carry all the molecules needed for activation of a T-cell immune response and can act alone as cell-free anti-tumor vaccines. To efficiently activate anti-tumor immune responses by DC-derived EVs, the proper choices of tumor antigens for the loading of EV-producing DCs and factors stimulating the maturation of DCs, are of great importance. Significant success in the treatment of tumors by DC-derived EVs has been achieved in murine tumor models in vivo and human cells ex vivo (see Table 2B).

The anti-tumor potential of cell-free vaccines based on murine DC-derived EVs indirectly loaded with a-fetoprotein (AFP) has been evaluated (Lu et al., 2017). It was demonstrated that AFP-EVs activate an efficient antigen-specific immune response that causes significant retardation of tumor growth and an increase in the overall survival of mice with hepatocellular carcinoma Hepa1-6. Together with these effects, AFP-EVs reshaped the tumor microenvironment by attracting $\mathrm{CD}^{+}$T-lymphocytes to tumor sites and causing an increase in the levels of the immunostimulatory cytokines IFN- $\gamma$ and IL-2 combined with reductions in immunosuppressive $\mathrm{CD} 25^{+} \mathrm{FoxP}^{+}$T-regulatory cells and the levels of the immunosuppressive cytokines IL-10 and TGF- $\beta$ (Lu et al., 2017).

Another tumor-associated antigen, HPV early antigen 7 peptide $\left(\mathrm{E}_{49-57}\right)$, which is the main target antigen in cervical cancer, was used to load murine EV-producing DCs (Chen et al., 2018). The treatment of TC- 1 cervical cancer-bearing mice with E7 ${ }_{49-57}$-loaded EVs induced an anti-tumor CTL response and activated potent protective and therapeutic immune responses in vivo (Chen et al., 2018).

Sources of multiple tumor antigens, such as tumor lysates or tumor total RNA, have advantages over single tumor antigens, since they contain a full set of tumor antigens and have the ability to activate a broad spectrum of polyclonal anti-tumor immune responses (Rizzo et al., 2014). Murine DC-derived EVs indirectly loaded with the lysate or chaperone-enriched lysate of GL261 mouse glioma cells have been obtained (Bu et al., 2015). DCs treated with EVs loaded with chaperone-enriched glioma lysate promoted the proliferation of $\mathrm{CD}^{+}$and $\mathrm{CD}^{+} \mathrm{T}$ cells and the activation of anti-tumor CTLs ex vivo, as well as the significant inhibition of tumor growth and prolonged survival of tumor-bearing mice. It was found that the chaperone-rich lysate contained at least four chaperone proteins including heat shock protein (Hsp) 70, Hsp 90, calreticulin, and glucose-regulated protein 94 (GRP94). Thus, chaperone-rich lysate is a superior source of tumor antigens for the loading of DCs and EVs in comparison with the lysate of tumor cells prepared using the conventional freezing-thawing method (Bu et al., 2015).

Human DC-derived EVs indirectly loaded with total tumor RNA or tumor lysate have been used to activate CTLs against human gastric adenocarcinoma BGC823 ex vivo (Guan et al., 2014). It was shown that DCs loaded with tumor RNA and EVs derived from these cells were more potent with respect to stimulating the proliferation of $\mathrm{T}$ cells and activated more efficient anti-tumor CTLs ex vivo in comparison with lysateloaded DCs and their EV derivatives. However, all tested DCs or EVs inoculated in combination with $\mathrm{T}$ cells into tumorbearing mice inhibited tumor growth with similar efficiency in a xenograft BGC823 tumor model (Guan et al., 2014).

The anti-tumor potential of T-cell vaccines stimulated with DC-derived EVs has been investigated (Wang et al., 2013). $\mathrm{CD}^{+} \mathrm{T}$ lymphocytes were primed with EVs isolated from DCs expressing HER2/Neu or HER2 tumor antigens ex vivo and used 
as anti-tumor immunotherapeutic vaccines. It was demonstrated that this immunotherapeutic approach provides significant results: efficient tumor-specific CTLs are activated and protective immunity is triggered in mice with $\mathrm{HER} 2 / \mathrm{Neu}^{+} \mathrm{Tg} 1-1$ breast cancer or HLA-A2+HER2 $2^{+}$B16-F10 melanoma.

Immunotherapeutic anti-tumor approaches have been widely investigated in tumor cells stably expressing ovalbumin (OVA), which are used as a useful model of tumor-specific antigens. OVA and the OVA-derived MHC I-restricted peptide, SIINFEKL, were used for the indirect loading of DC-derived EVs, and it was demonstrated that only OVAloaded EVs, but not EVs loaded with the OVA-derived MHC I-restricted peptide, caused the induction of OVA-specific cytotoxic $\mathrm{CD}^{+} \mathrm{T}$ cells in vivo. The activation of CTLs was dependent on OVA-specific CD4 ${ }^{+} \mathrm{T}$ cells and B lymphocytes, since the full-length OVA protein contains both Th- and B-cell epitopes, whereas the SIINFEKL peptide is $\mathrm{CD}^{+} \mathrm{T}$ cell-specific. OVA-loaded EVs were superior in protecting the mice against B16-OVA tumor growth in comparison with peptide-loaded EVs (Naslund et al., 2013). A subsequent study by the same scientific group was devoted to comparing the ability of small- and large-sized EV s produced by OVA-loaded DCs to stimulate OVA-specific immune responses (Wahlund et al., 2017). Small-sized EVs (exosomes precipitated by ultracentrifugation at $100,000 \mathrm{~g}$ ) carried high levels of intact OVA inside and OVA peptides on their surface, whereas large-sized EVs (MVs pelleted by centrifugation at 10,000g) contained barely detectable levels of OVA. OVA-loaded smallsized EVs were shown to induce more potent OVA-specific Tand B-lymphocyte immune responses in vivo in comparison with large-sized EVs (Wahlund et al., 2017). It should be mentioned that small-sized EVs derived from immature DCs were shown to interact with T cells via CD80 signaling, inducing the secretion of Th1 cytokines (IFN- $\gamma$ ), whereas large-sized EVs induced Th2 cytokine synthesis (IL-4, IL-5, and IL-13) via CD40 signaling. Maturation of EV-producing DCs with LPS abolished the functional differences between small- and large-sized EVs: both types of EVs induced Th1specific IFN- $\gamma$ synthesis (Tkach et al., 2017).

DC-derived EVs have been indirectly loaded with a combination of model antigens, OVA and a-galactosylceramide $(a \mathrm{GC})$, the latter of which is a ligand of invariant NKT cells (iNKT cells). Such EV s induced potent innate (NK and $\gamma \delta$ T lymphocytes) and OVA-specific T- and B-cell adaptive immune responses in vitro and in vivo. Using a mouse B16-OVA melanoma model it was demonstrated that DC-derived EVs loaded with OVA/ aGC caused significant retardation of tumor growth, promoted infiltration of tumor tissues with antigen-specific $\mathrm{CD}^{+} \mathrm{T}$ cells, and increased the median survival time of tumor-bearing mice in comparison with those treated with a combination of soluble OVA and aGC (Gehrmann et al., 2013).

Undoubtedly, NK cells play a significant role in tumor immunosuppression; therefore, the potent anti-tumor potential of DC-derived EVs to activate NK cells and induce adaptive immunity is of great importance. EVs produced by nonloaded mouse DCs and EVs secreted by human DCs loaded with MAGE3 peptides have been used to treat mouse YAC-1 lymphoma and human advanced melanoma (stages IIIb and V) in phase I clinical trials. It was demonstrated that both mouse and human DC-derived EVs carried functional IL-15Ra receptors that could transpresent IL-15 to NK cells to stimulate their activation, proliferation, and IFN- $\gamma$ synthesis in vitro and in vivo. Additionally, activation of NK cells was shown to occur via the interaction of NKG2D ligands (ULBP-1, MICA/B), carried on the surface of DC-derived EVs, with NKG2D receptors on NK cells (Viaud et al., 2009). NK cells can also be activated through the interaction of TNF receptors on NK cells with TNF ligands expressed on the surface of DCs and their EVs. It has been clearly demonstrated that even intact EVs produced by mature DCs carrying transmembrane TNF are able to activate NK cells and stimulate IFN- $\gamma$ synthesis (Munich et al., 2012). Furthermore, these EVs were shown to express other TNF superfamily ligands, such as FasL and TRAIL, and cause the direct induction of apoptosis of B16 melanoma, KLN205 lung squamous cell carcinoma, and MC38 colon adenocarcinoma cells in vitro (Munich et al., 2012). It has also been demonstrated that DC-derived EVs can bind LPS and Pam3CSK4, ligands of toll-like receptors (TLR) 4 and TLR1/2, respectively. DCs loaded with such EVs were shown to upregulate the expression of transmembrane TNF, activate NK cells, and stimulate NK cells to secrete of IFN- $\gamma$ (Sobo-Vujanovic et al., 2014).

The level of anti-tumor immune response triggered by DC-derived EVs directly depends on the degree of maturity of DCs and the type of maturation stimuli. The anti-tumor potential of EVs derived from murine DCs loaded with OVA or HOCloxidized B16-OVA cells that were matured with poly(I:C) (TLR3 ligand), LPS (TLR4 ligand), and CpG-B oligonucleotide (TLR9 ligand) have been compared in a model of B16-OVA melanoma in vivo (Damo et al., 2015). It was demonstrated that all types of EVs were able to significantly retard tumor growth. However, EVs derived from necrotic B16 cell-loaded DCs treated with poly(I:C) were the most efficient and induced robust activation of melanoma-specific CD ${ }^{+} \mathrm{T}$ cells in tumor-draining lymph nodes, spleen, and tumor tissues and recruited NK and NK-T cells to the tumor site, resulting in drastic inhibition of tumor growth and an increase in survival in tumor-bearing animals (Damo et al., 2015). Moreover, EVs produced by poly(I:C)-matured DCs loaded with HPV early antigen 7 markedly inhibited murine TC-1 cervical tumor growth and improved the survival rate of tumor-bearing mice (Chen et al., 2018). Thus, it has been revealed that the TLR3 ligand poly(I:C) is a favourable TLR agonist for DC maturation during antigen loading, which significantly increased the potential for anti-tumor immunity induced by antigen-loaded EVs, and could be suggested as a promising maturation stimulus for DC-derived EVs.

EVs produced by heat shock-exposed DCs and tumor cells have proven themselves as efficient immunotherapeutic vaccines. Tumor cells are characterized by the unusual overexpression of heat-shock proteins, such as HSP70, HSP90, and HSP72, which protect tumor cells from apoptosis induction (Ferrarini et al., 1992; Jäättelä et al., 1992). Thus, these heat-shock proteins can serve as tumor-specific antigens to activate anti-tumor immune 
responses. Heat-stressed EVs (HS-EVs) are commonly isolated from DCs or tumor cells that are exposed to hyperthermia at $42^{\circ} \mathrm{C}$ to $43^{\circ} \mathrm{C}$ for 1 to $4 \mathrm{~h}$ in vitro (Chen et al., 2011; Zhong et al., 2011; Wang et al., 2015) or from human tumor cells isolated following induction of hyperthermia in patients at $39^{\circ} \mathrm{C}$ for $1 \mathrm{~h}$ (Guo et al., 2018). HS-EVs contained high levels of HSP70 and HSP60, indicating significant immunotherapeutic properties (Zhong et al., 2011). Such HS-EVs promoted maturation of DCs, activated proliferation of T-lymphocytes, and induced tumorspecific immune responses in vivo (Zhong et al., 2011; Guo et al., 2018). HS-EVs were also shown to contain the chemokines CCL2, CCL3, CCL4, CCL5, and CCL20, which chemoattracted $\mathrm{CD} 11 \mathrm{c}^{+} \mathrm{DCs}$ and $\mathrm{CD} 4^{+/} \mathrm{CD}^{+} \mathrm{T}$ cells into tumor tissues in vivo (Chen et al., 2011). DCs treated with HS-EVs were able to convert immunosuppressive T-regulatory cells to Th17 cells, contributing to the rejection of established prostate cancer in mice (Guo et al., 2018).

As it has been reviewed above, accumulated material on the potential of DC-derived EVs confirmed that these EVs are able to directly initiate strong anti-tumor innate and adaptive immune responses in vivo, protect experimental animals against tumors in prophylactic settings, and significantly reduce tumor growth and metastasis in therapeutic regimen.

Furthermore, the immunogenic potential of DC-derived EVs has been clearly demonstrated in phase I and II clinical trials (Escudier et al., 2005; Morse et al., 2005; Dai et al., 2008; Viaud et al., 2009; Besse et al., 2016) (see Table 2C). DC-derived EVs were shown to be safe for patients and to stimulate anti-tumor CTLs and NK cells. However, the actual clinical potential of DC-derived EVs to trigger anti-tumor immune responses, reduce tumor size and metastasis, and increase the survival time in patients remains undefined. It is hoped that DC-derived EVs will be more successful anti-tumor vaccines in comparison with DC-derived vaccines.

\section{CONCLUDING REMARKS-EVS PROBLEMS AND OPENED QUESTIONS}

As mentioned above, great success is achieved on application of DC-targeted/-derived EVs to treat tumors in different murine tumor models and promising results are obtained in phase I and II clinical trials. Experimental data obtained to date points to similar or even superior ability of DC-targeted or DC-derived EVs to activate anti-tumor immune responses in comparison with classic DC-based vaccines. To enhance the anti-tumor and immunogenic potential of EVs, they are modified with a variety of molecules, such as tumor-associated antigens, tumoror DC-targeted molecules, small non-coding regulatory RNA, and immunostimulatory molecules. Almost all methods of EV modification to possess anti-tumor properties are considered in the present review.

Nevertheless, some problems and opened questions on antitumor application of EV-based vaccines are still unsolved.

First, physiological activity of EVs is still poorly understood. In general, it is not yet entirely clear how EV-mediated paracrine regulation between cells occurs. The mechanism of selection of biologically active molecules (such as miRNA, cytokines, peptides, etc.) to EVs is not completely elucidated. Data on targeted delivery of natural EVs to specific cells and tissues are insufficient. Therefore, further comprehensive and in-depth investigations of biological properties of EVs are of immediate interest.

One of the main problems of EVs to investigate their biological properties and use them in clinical trials is inability of modern methods to isolate pure fractions of EVs without any mixture of residual subpopulations of other vesicles or even non-vesicular particles (Chulpanova et al., 2018). Hence, it is challenging to establish Clinical Good Manufacturing Practice (cGMP)-grade EVs preparations. Novel isolation methods are required to enrichment of the specific EVs subtypes. Therefore, better knowledge of specific markers of EVs subtypes is required.

Application of EV-based anti-tumor vaccines is associated with additional questions. How should dosing of inoculated EVs be determined? It is known that EV-mediated signaling is dose-dependent (Yu et al., 2007), so variation of EVs dose is able to impact on the balance between deleterious and therapeutic potential of administered EVs. In addition, does the route of administration (subcutaneous, intradermal, intravenous, etc.) impact the efficiency of EV-based antitumor therapy?

Additionally, to prepare sufficient amounts of therapeutic EVs, a big number of EV-producing cells and a huge volume of EV-containing condition media should be processed, that significantly complicates technological process and increases the price of potential antitumor EV-based vaccine. Highly scalable methods for mass production of EVs are required at all stages of the manufacturing process.

Finally, targeting of EVs to specific cells and tissues requires further optimization, as well as more efficient techniques for loading EVs with NAs, proteins, lipids should be developed.

In the near future these problems and questions will need to solve by enthusiastic multidisciplinary collaboration of molecular biologists, immunologists, biochemists, together with physicians to develop highly efficient next generation of EV-based antitumor vaccines.

\section{AUTHOR CONTRIBUTIONS}

OM analyzed published data and prepared the manuscript. AO prepared the part of the manuscript devoted to delivery of nucleic acids using extracellular vesicles. NM revised and corrected the manuscript.

\section{FUNDING}

The present work was funded by the Russian Science Foundation (grant 17-74-10144) (OM), the Russian Foundation for Basic Research [grants 17-04-01136 (AO), 17-04-00999 (NM)], and the Russian State funded budget project of ICBFM SB RAS AAAA-A17-117020210024-8 (NM). 


\section{REFERENCES}

Alvarez-Erviti, L., Seow, Y., Yin, H., Betts, C., Lakhal, S., and Wood, M. J. A. (2011). Delivery of siRNA to the mouse brain by systemic injection of targeted exosomes. Nat. Biotechnol. 29, 341-345. doi: 10.1038/nbt.1807

André, F., Schartz, N. E. C., Chaput, N., Flament, C., Raposo, G., Amigorena, S., et al. (2002). Tumor-derived exosomes: a new source of tumor rejection antigens. Vaccine 20, A28-A31. doi: 10.1016/S0264-410X(02)00384-5

Anticoli, S., Aricò, E., Arenaccio, C., Manfredi, F., Chiozzini, C., Olivetta, E., et al. (2018). Engineered exosomes emerging from muscle cells break immune tolerance to HER2 in transgenic mice and induce antigen-specific CTLs upon challenge by human dendritic cells. J. Mol. Med. 96, 211-221. doi: 10.1007/ s00109-017-1617-2

Asadirad, A., Hashemi, S. M., Baghaei, K., Ghanbarian, H., Mortaz, E., Zali, M. R., et al. (2019). Phenotypical and functional evaluation of dendritic cells after exosomal delivery of miRNA-155. Life Sci. 219, 152-162. doi: 10.1016/j. lfs.2019.01.005

Bapsy, P. P., Sharan, B., Kumar, C., Das, R. P., Rangarajan, B., Jain, M., et al. (2014). Open-label, multi-center, non-randomized, single-arm study to evaluate the safety and efficacy of dendritic cell immunotherapy in patients with refractory solid malignancies, on supportive care. Cytotherapy 16, 234-244. doi: 10.1016/j. jcyt.2013.11.013

Batrakova, E. V., and Kim, M. S. (2015). Using exosomes, naturally-equipped nanocarriers, for drug delivery. J. Control. Release 219, 396-405. doi: 10.1016/j. jconrel.2015.07.030

Bellavia, D., Raimondo, S., Calabrese, G., Forte, S., Cristaldi, M., Patinella, A., et al. (2017). Interleukin 3- receptor targeted exosomes inhibit in vitro and in vivo chronic myelogenous Leukemia cell growth. Theranostics 7, 1333-1345. doi: 10.7150/thno.17092

Besse, B., Charrier, M., Lapierre, V., Dansin, E., Lantz, O., Planchard, D., et al. (2016). Dendritic cell-derived exosomes as maintenance immunotherapy after first line chemotherapy in NSCLC. Oncoimmunology 5, 1-13. doi: 10.1080/2162402X.2015.1071008

Bu, N., Wu, H., Sun, B., Zhang, G., Zhan, S., Zhang, R., et al. (2011). Exosomeloaded dendritic cells elicit tumor-specific CD8+cytotoxic T cells in patients with glioma. J. Neurooncol. 104, 659-667. doi: 10.1007/s11060-011-0537-1

Bu, N., Wu, H., Zhang, G., Zhan, S., Zhang, R., Sun, H., et al. (2015). Exosomes from dendritic cells loaded with chaperone-rich cell lysates elicit a potent $\mathrm{T}$ cell immune response against intracranial glioma in mice. J. Mol. Neurosci. 56, 631-643. doi: 10.1007/s12031-015-0506-9

Chaput, N., Flament, C., Viaud, S., Taieb, J., Roux, S., Spatz, A., et al. (2006). Dendritic cell derived-exosomes: biology and clinical implementations. J. Leukoc. Biol. 80, 471-478. doi: 10.1189/jlb.0206094

Chen, S., Lv, M., Fang, S., Ye, W., Gao, Y., and Xu, Y. (2018). Poly(I:C) enhanced anti-cervical cancer immunities induced by dendritic cells-derived exosomes. Int. J. Biol. Macromol. 113, 1182-1187. doi: 10.1016/j.ijbiomac.2018.02.034

Chen, T., Guo, J., Yang, M., Zhu, X., and Cao, X. (2011). Chemokine-containing exosomes are released from heat-stressed tumor cells via lipid raft-dependent pathway and act as efficient tumor vaccine. J. Immunol. 186, 2219-2228. doi: 10.4049/jimmunol.1002991

Chulpanova, D. S., Kitaeva, K. V., James, V., Rizvanov, A. A., and Solovyeva, V. V. (2018). Therapeutic prospects of extracellular vesicles in cancer treatment. Front. Immunol. 9, 1534. doi: 10.3389/fimmu.2018.01534

Clayton, A., Mitchell, J. P., Court, J., Linnane, S., Mason, M. D., and Tabi, Z. (2008). Human tumor-derived exosomes down-modulate NKG2D expression. J. Immunol. 180, 7249-7258. doi: 10.4049/jimmunol.180.11.7249

Colombo, M., Raposo, G., and Théry, C. (2014). Biogenesis, secretion, and intercellular interactions of exosomes and other extracellular vesicles. Annu. Rev. Cell Dev. Biol. 30, 255-289. doi: 10.1146/annurev-cellbio-101512-122326

Constantino, J., Gomes, C., Falcão, A., Cruz, M. T., and Neves, B. M. (2016). Antitumor dendritic cell-based vaccines: lessons from 20 years of clinical trials and future perspectives. Transl. Res. 168, 74-95. doi: 10.1016/j. trsl.2015.07.008

Cooper, J. M., Wiklander, P. B. O., Nordin, J. Z., Al-Shawi, R., Wood, M. J., Vithlani, M., et al. (2014). Systemic exosomal siRNA delivery reduced alphasynuclein aggregates in brains of transgenic mice. Mov. Disord. 29, 1476-1485. doi: $10.1002 / \mathrm{mds} .25978$
Dai, S., Wei, D., Wu, Z., Zhou, X., Wei, X., Huang, H., et al. (2008). Phase I clinical trial of autologous ascites-derived exosomes combined with GM-CSF for colorectal cancer. Mol. Ther. 16, 782-790. doi: 10.1038/mt.2008.1

Damo, M., Wilson, D. S., Simeoni, E., and Hubbell, J. A. (2015). TLR-3 stimulation improves anti-tumor immunity elicited by dendritic cell exosome-based vaccines in a murine model of melanoma. Sci. Rep. 5, 1-15. doi: 10.1038/ srep 17622

Dhodapkar, M. V., Steinman, R. M., Sapp, M., Desai, H., Fossella, C., Krasovsky, J., et al. (1999). Rapid generation of broad T-cell immunity in humans after a single injection of mature dendritic cells. J. Clin. Invest. 104, 173-180. doi: 10.1172/JCI6909

Diamond, J. M., Vanpouille-Box, C., Spada, S., Rudqvist, N.-P., Chapman, J. R., Ueberheide, B. M., et al. (2018). Exosomes shuttle TREX1-sensitive IFNstimulatory dsDNA from irradiated cancer cells to DCs. Cancer Immunol. Res. 6, 910-920. doi: 10.1158/2326-6066.CIR-17-0581

Didiot, M.-C., Hall, L. M., Coles, A. H., Haraszti, R. A., Godinho, B. M., Chase, K., et al. (2016). Exosome-mediated delivery of hydrophobically modified siRNA for Huntingtin mRNA silencing. Mol. Ther. 24, 1836-1847. doi: 10.1038/ mt.2016.126

Escudier, B., Dorval, T., Chaput, N., André, F., Caby, M. P., Novault, S., et al. (2005). Vaccination of metastatic melanoma patients with autologous dendritic cell (DC) derived-exosomes: results of the first phase 1 clinical trial. J. Transl. Med. 3, 10. doi: 10.1186/1479-5876-3-10

Fang, F., Xiao, W., and Tian, Z. (2017). NK cell-based immunotherapy for cancer. Semin. Immunol. 31, 37-54. doi: 10.1016/j.smim.2017.07.009

Ferrarini, M., Heltai, S., Zocchi, M. R., and Rugarli, C. (1992). Unusual expression and localization of heat-shock proteins in human tumor cells. Int. J. Cancer 51, 613-619. doi: 10.1002/ijc.2910510418

Gehrmann, U., Hiltbrunner, S., Georgoudaki, A. M., Karlsson, M. C., Näslund, T. I., and Gabrielsson, S. (2013). Synergistic induction of adaptive antitumor immunity by codelivery of antigen with a-galactosylceramide on exosomes. Cancer Res. 73, 3865-3876. doi: 10.1158/0008-5472.CAN-12-3918

George, J., Yan, I. K., and Patel, T. (2018). Nanovesicle-mediated delivery of anticancer agents effectively induced cell death and regressed intrahepatic tumors in athymic mice. Lab. Investig. 98, 895-910. doi: 10.1038/ s41374-018-0053-4

Gu, X., Erb, U., Büchler, M. W., and Zöller, M. (2015). Improved vaccine efficacy of tumor exosome compared to tumor lysate loaded dendritic cells in mice. Int. J. Cancer 136, E74-E84. doi: 10.1002/ijc.29100

Guan, S., Li, Q., Liu, P., Xuan, X., and Du, Y. (2014). Umbilical cord bloodderived dendritic cells loaded with BGC823 tumor antigens and DC-derived exosomes stimulate efficient cytotoxic T-lymphocyte responses and antitumor immunity in vitro and in vivo. Cent. Eur. J. Immunol. 39, 142-151. doi: 10.5114/ ceji.2014.43713

Gulinelli, S., Salaro, E., Vuerich, M., Bozzato, D., Pizzirani, C., Bolognesi, G., et al. (2012). IL-18 associates to microvesicles shed from human macrophages by a LPS/TLR-4 independent mechanism in response to $\mathrm{P} 2 \mathrm{X}$ receptor stimulation. Eur. J. Immunol. 42, 3334-3345. doi: 10.1002/eji.201142268

Guo, D., Chen, Y., Wang, S., Yu, L., Shen, Y., Zhong, H., et al. (2018). Exosomes from heat-stressed tumour cells inhibit tumour growth by converting regulatory $\mathrm{T}$ cells to Th17 cells via IL-6. Immunology 154, 132-143. doi: 10.1111/imm.12874

Gurunathan, S., Kang, M.-H., Jeyaraj, M., Qasim, M., and Kim, J.-H. (2019). Review of the Isolation, characterization, biological function, and multifarious therapeutic approaches of exosomes. Cells 8, 307. doi: 10.3390/cells8040307

Ha, D., Yang, N., and Nadithe, V. (2016). Exosomes as therapeutic drug carriers and delivery vehicles across biological membranes: current perspectives and future challenges. Acta Pharm. Sin. B 6, 287-296. doi: 10.1016/j.apsb.2016.02.001

Haney, M. J., Klyachko, N. L., Zhao, Y., Gupta, R., Plotnikova, E. G., He, Z., et al. (2015). Exosomes as drug delivery vehicles for Parkinson's disease therapy. J. Control. Release 207, 18-30. doi: 10.1016/j.jconrel.2015.03.033

Hartman, Z. C., Wei, J., Glass, O. K., Guo, H., Lei, G., Yang, X. Y., et al. (2011). Increasing vaccine potency through exosome antigen targeting. Vaccine 29, 9361-9367. doi: 10.1016/j.vaccine.2011.09.133

Helwa, I., Cai, J., Drewry, M. D., Zimmerman, A., Dinkins, M. B., Khaled, M. L., et al. (2017). A comparative study of serum exosome isolation using differential ultracentrifugation and three commercial reagents. PLoS One 12 (1), e0170628. doi: 10.1371/journal.pone.0170628 
Hsu, D.-H., Mehta-Damani, A., Angevin, E., Le Pecq, J.-B., Rivas, A., Villaflor, G., et al. (2003). Exosomes as a tumor vaccine: enhancing potency through direct loading of antigenic peptides. J. Immunother. 26, 440-450. doi: 10.1097/00002371-200309000-00007

Huang, F., Wan, J., Hao, S., Deng, X., Chen, L., and Ma, L. (2017). TGF- $\beta 1$-silenced leukemia cell-derived exosomes target dendritic cells to induce potent antileukemic immunity in a mouse model. Cancer Immunol. Immunother. 66, 1321-1331. doi: 10.1007/s00262-017-2028-5

Huang, S., Li, Y., Zhang, J., Rong, J., and Ye, S. (2013). Epidermal growth factor receptor-containing exosomes induce tumor-specific regulatory T cells. Cancer Insestigation 31, 330-335. doi: 10.3109/07357907.2013.789905

Jäättelä, M., Wissing, D., Bauer, P. A., and Li, G. C. (1992). Major heat shock protein hsp70 protects tumor cells from tumor necrosis factor cytotoxicity. EMBO J. 11, 3507-3512. doi: 10.1002/j.1460-2075.1992.tb05433.x

Jeyaram, A., and Jay, S. M. (2018). Preservation and Storage Stability of Extracellular Vesicles for Therapeutic Applications. AAPS J. 20, 1. doi: 10.1208/ s12248-017-0160-y

Jiang, L., Vader, P., and Schiffelers, R. M. (2017). Extracellular vesicles for nucleic acid delivery: progress and prospects for safe RNA-based gene therapy. Gene Ther. 24, 157-166. doi: 10.1038/gt.2017.8

Johnsen, K. B., Gudbergsson, J. M., Skov, M. N., Pilgaard, L., Moos, T., and Duroux, M. (2014). A comprehensive overview of exosomes as drug delivery vehicles - Endogenous nanocarriers for targeted cancer therapy. Biochim. Biophys. Acta - Rev. Cancer 1846, 75-87. doi: 10.1016/j.bbcan.2014.04.005

Kantoff, P. W., Higano, C. S., Shore, N. D., Berger, E. R., Small, E. J., Penson, D. F., et al. (2010). Sipuleucel-T immunotherapy for castration-resistant prostate cancer. N. Engl. J. Med. 363, 411-422. doi: 10.1056/NEJMoa1001294

Kapsenberg, M. L. (2003). Dendritic-cell control of pathogen-driven T-cell polarization. Nat. Rev. Immunol. 3, 984-993. doi: 10.1038/nri1246

Katakowski, M., Buller, B., Zheng, X., Lu, Y., Rogers, T., Osobamiro, O., et al. (2013). Exosomes from marrow stromal cells expressing miR-146b inhibit glioma growth. Cancer Lett. 335, 201-204. doi: 10.1016/j.canlet.2013.02.019

Kooijmans, S. A. A., Stremersch, S., Braeckmans, K., de Smedt, S. C., Hendrix, A., Wood, M. J. A., et al. (2013). Electroporation-induced siRNA precipitation obscures the efficiency of siRNA loading into extracellular vesicles. J. Control. Release 172, 229-238. doi: 10.1016/j.jconrel.2013.08.014

Kumar, C., Kohli, S., Chiliveru, S., Bapsy, P. P., Jain, M., Attili, V. S. S., et al. (2017). A retrospective analysis comparing APCEDEN ${ }^{\circledR}$ dendritic cell immunotherapy with best supportive care in refractory cancer. Immunotherapy 9, 889-897. doi: 10.2217/imt-2017-0064

Lamichhane, T. N., Jeyaram, A., Patel, D. B., Parajuli, B., Livingston, N. K., Arumugasaamy, N., et al. (2016). Oncogene knockdown via active loading of small RNAs into extracellular vesicles by sonication. Cell Mol. Bioeng. 9, 315324. doi: 10.1007/s12195-016-0457-4

Langerhans, P. (1868). Ueber die Nerven der menschlichen Haut. Arch. für Pathol. Anat. und Physiol. und für Klin. Med. 44, 325-337. doi: 10.1007/BF01959006

Lattanzi, L., and Federico, M. (2012). A strategy of antigen incorporation into exosomes: comparing cross-presentation levels of antigens delivered by engineered exosomes and by lentiviral virus-like particles. Vaccine 30, 72297237. doi: 10.1016/j.vaccine.2012.10.010

Lee, T. H., D’Asti, E., Magnus, N., Al-Nedawi, K., Meehan, B., and Rak, J. (2011). Microvesicles as mediators of intercellular communication in cancer-the emerging science of cellular “debris". Semin. Immunopathol. 33, 455-467. doi: 10.1007/s00281-011-0250-3

Li, P., Kaslan, M., Lee, S. H., Yao, J., and Gao, Z. (2017). Progress in exosome isolation techniques. Theranostics 7, 789-804. doi: 10.7150/thno.18133

Li, W., Mu, D., Tian, F., Hu, Y., Jiang, T., Han, Y., et al. (2013). Exosomes derived from Rab27a-overexpressing tumor cells elicit efficient induction of antitumor immunity. Mol. Med. Rep. 8, 1876-1882. doi: 10.3892/mmr.2013.1738

Lin, T. J., Liang, W. M., Hsiao, P. W., Pradeep, M. S., Wei, W. C., Lin, H. T., et al. (2015). Rapamycin promotes mouse $4 \mathrm{~T} 1$ tumor metastasis that can be reversed by a dendritic cell-based vaccine. PLoS One 10, e0138335. doi: 10.1371/journal. pone. 0138335

Liu, G., Fan, X., Cai, Y., Fu, Z., Gao, F., Dong, J., et al. (2019). Efficacy of dendritic cell-based immunotherapy produced from cord blood in vitro and in a humanized NSG mouse cancer model. Immunotherapy 11, 599-616. doi: 10.2217/imt-2018-0103
Liu, H., Chen, L., Peng, Y., Yu, S., Liu, J., Wu, L., et al. (2018). Dendritic cells loaded with tumor derived exosomes for cancer immunotherapy. Oncotarget 9, 28872894. doi: 10.18632/oncotarget.20812

Liu, Y., Li, D., Liu, Z., Zhou, Y., Chu, D., Li, X., et al. (2015). Targeted exosomemediated delivery of opioid receptor Mu siRNA for the treatment of morphine relapse. Sci. Rep. 5, 17543. doi: 10.1038/srep17543

Lu, Z., Zuo, B., Jing, R., Gao, X., Rao, Q., Liu, Z., et al. (2017). Dendritic cell-derived exosomes elicit tumor regression in autochthonous hepatocellular carcinoma mouse models. J. Hepatol. 67, 739-748. doi: 10.1016/j.jhep.2017.05.019

Lundholm, M., Schröder, M., Nagaeva, O., Baranov, V., Widmark, A., MinchevaNilsson, L., et al. (2014). Prostate tumor-derived exosomes down-regulate NKG2D expression on natural killer cells and CD8+ T cells: mechanism of immune evasion. PLoS One 9, e108924. doi: 10.1371/journal.pone.0108925

Lutz, M. B., and Schuler, G. (2002). Immature, semi-mature and fully mature dendritic cells: which signals induce tolerance or immunity? Trends Immunol. 23, 445-449. doi: 10.1016/S1471-4906(02)02281-0

Mahaweni, N. M., Kaijen-Lambers, M. E. H., Dekkers, J., Aerts, J. G. J. V., and Hegmans, J. P. J. J. (2013). Tumour-derived exosomes as antigen delivery carriers in dendritic cell-based immunotherapy for malignant mesothelioma. J. Extracell. Vesicles 2, 1. doi: 10.3402/jev.v2i0.22492

Markov, O. V., Mironova, N. L., Vlasov, V. V., and Zenkova, M. A. (2016). Molecular and cellular mechanisms of antitumor immune response activation by dendritic cells. Acta Naturae 8, 17-30. doi: 10.32607/20758251-2016-8-3-17-30

Markov, O. V., Mironova, N. L., Vlassov, V. V., and Zenkova, M. A. (2017). Antitumor vaccines based on dendritic cells: from experiments using animal tumor models to clinical trials. Acta Naturae 9, 27-38. doi: 10.32607/20758251-2017-9-3-27-38

Mastelic-Gavillet, B., Balint, K., Boudousquie, C., Gannon, P. O., and Kandalaft, L. E. (2019). Personalized dendritic cell vaccines-recent breakthroughs and encouraging clinical results. Front. Immunol. 10, 766. doi: 10.3389/fimmu.2019.00766

Merad, M., Ginhoux, F., and Collin, M. (2008). Origin, homeostasis and function of Langerhans cells and other langerin-expressing dendritic cells. Nat. Rev. Immunol. 8, 935-947. doi: 10.1038/nri2455

Morel, O., Jesel, L., Freyssinet, J. M., and Toti, F. (2011). Cellular mechanisms underlying the formation of circulating microparticles. Arterioscler. Thromb. Vasc. Biol. 31, 15-26. doi: 10.1161/ATVBAHA.109.200956

Morelli, A. E., Larregina, A. T., Shufesky, W. J., Sullivan, M. L. G., Stolz, D. B., Papworth, G. D., et al. (2004). Endocytosis, intracellular sorting, and processing of exosomes by dendritic cells. Blood 104, 3257-3266. doi: 10.1182/ blood-2004-03-0824

Morishita, M., Takahashi, Y., Matsumoto, A., Nishikawa, M., and Takakura, Y. (2016). Exosome-based tumor antigens-adjuvant co-delivery utilizing genetically engineered tumor cell-derived exosomes with immunostimulatory CpG DNA. Biomaterials 111, 55-65. doi: 10.1016/j.biomaterials.2016.09.031

Morishita, M., Takahashi, Y., Nishikawa, M., Ariizumi, R., and Takakura, Y. (2017). Enhanced Class i Tumor Antigen Presentation via Cytosolic Delivery of Exosomal Cargos by Tumor-Cell-Derived Exosomes Displaying a pH-Sensitive Fusogenic Peptide. Mol. Pharm. 14, 4079-4086. doi: 10.1021/acs. molpharmaceut.7b00760

Morse, M. A., Garst, J., Osada, T., Khan, S., Hobeika, A., Clay, T. M., et al. (2005). A phase I study of dexosome immunotherapy in patients with advanced nonsmall cell lung cancer. J. Transl. Med. 3, 1-8. doi: 10.1186/1479-5876-3-9

Munich, S., Sobo-Vujanovic, A., Buchser, W. J., Beer-Stolz, D., and Vujanovic, N. L. (2012). Dendritic cell exosomes directly kill tumor cells and activate natural killer cells via TNF superfamily ligands. Oncoimmunology 1, 1074-1083. doi: 10.4161/onci.20897

Naslund, T. I., Gehrmann, U., Qazi, K. R., Karlsson, M. C. I., and Gabrielsson, S. (2013). Dendritic Cell-Derived Exosomes Need To Activate Both T and B Cells To Induce Antitumor Immunity. J. Immunol. 190, 2712-2719. doi: 10.4049/ jimmunol.1203082

NCT03092453. (2017). Mature dendritic cell vaccination against mutated antigens in patients with advanced melanoma.

NCT03152565. (2017). A single arm phase i-ii multicenter trial with avelumab plus autologous dendritic cell vaccine to determine safety and preliminary efficacy of the combination in pre-treated mismatch repair-proficient (MSS) metastatic colorectal cancer patients. 
NCT00639639. (2008). Anti-tumor immunotherapy targeted against cytomegalovirus in patients with newly-diagnosed glioblastoma multiforme during recovery from therapeutic temozolomide-induced lymphopenia.

NCT00703105. (2008). Defining the role of CD4+CD25+ immunoregulatory T-cells in the treatment of patients with advanced ovarian cancer who receive dendritic cell based vaccine therapies.

NCT00799110. (2008). Vaccination of patients with ovarian cancer with dendritic cell/tumor fusions with GM-CSF and imiquimod.

NCT01204684. (2010). A phase II clinical trial evaluating autologous dendritic cells pulsed with tumor lysate antigen $+/$ - Toll-like receptor agonists for the treatment of malignant glioma.

NCT01159288. (2010). Phase II trial of a vaccination with tumor antigen-loaded dendritic cell-derived exosomes on patients with unresectable non small cell lung cancer responding to induction chemotherapy.

NCT01808820. (2013). Dendritic cell vaccine for malignant glioma and glioblastoma multiforme in adult and pediatric subjects.

NCT01885702. (2013). Dendritic cell vaccination in patients with lynch syndrome or colorectal cancer with MSI.

NCT01946373. (2013). A phase I study to evaluate safety, feasibility and immunologic response of adoptive $\mathrm{T}$ cell transfer with or without dendritic cell vaccination in patients with metastatic melanoma.

NCT01957956. (2013). Pilot clinical trial of allogeneic tumor lysate-pulsed autologous dendritic cell vaccination in newly diagnosed glioblastoma.

NCT01973322. (2013). Vaccination with autologous dendritic cells loaded with autologous tumor lysate or homogenate combined with immunomodulating radiotherapy and/or preleukapheresis IFN-alfa in patients with metastatic melanoma: a randomized "proof-of-principle" phase II study (ABSIDE).

NCT01983748. (2013). A non-commercial, multicenter, randomized, two-armed, open-label phase iii study to evaluate the adjuvant vaccination with tumor rnaloaded autologous dendritic cells versus observation of patients with resected monosomy 3 uveal melanoma.

NCT02301611. (2014). A prospective, randomized, blinded, placebo-controlled, phase IIb trial of an autologous tumor lysate $(\mathrm{TL})+$ yeast cell wall particles (YCWP) + dendritic cells (DC) vaccine vs unloaded YCWP + DC and embedded phase I/IIa trial with tumor lysate particle only (TLPO) vaccine in stage III and stage IV (resected) melanoma to prevent recurrence.

NCT02503150. (2015). Phase III trial of antigen pulsed dendritic cells (APDC) combined with chemotherapy in metastatic colorectal cancer.

NCT02529072. (2015). AVeRT: anti-PD-1 monoclonal antibody (Nivolumab) in combination with DC vaccines for the treatment of recurrent grade III and grade IV brain tumors.

NCT02678741. (2016). Multi-center phase I/IIa trial of an autologous tumor lysate $(\mathrm{TL})+$ yeast cell wall particles $(\mathrm{YCWP})+$ dendritic cells $(\mathrm{DC})$ vaccine in addition to standard of care checkpoint inhibitor of choice in metastatic melanoma patients with measurable disease.

NCT02718391. (2016). Complementary vaccination with dendritic cells pulsed with autologous tumor lysate in resected stage III and IV melanoma patients (ACDC).

NCT03014804. (2017). A phase II clinical trial evaluating combination therapy using DCVax-L (autologous dendritic cells pulsed with tumor lysate antigen) and Nivolumab (an anti-PD-1 antibody) for subjects with recurrent glioblastoma multiforme.

NCT03360708. (2017). Pilot clinical trial of allogeneic tumor lysate-pulsed autologous dendritic cell vaccination in recurrent glioblastoma.

NCT03406715. (2018). Combination immunotherapy with ipilimumab and nivolumab plus a dendritic cell based p53 vaccine (Ad.p53-DC) in patients with relapsed small cell lung cancer (SCLC).

Ning, Y., Shen, K., Wu, Q., Sun, X., Bai, Y., Xie, Y., et al. (2018). Tumor exosomes block dendritic cells maturation to decrease the $\mathrm{T}$ cell immune response. Immunol. Lett. 199, 36-43. doi: 10.1016/j.imlet.2018.05.002

Nussenzweig, M. C., Steinman, R. M., Gutchinov, B., and Cohn, Z. A. (1980). Dendritic cells are accessory cells for the development of anti-trinitrophenyl cytotoxic T lymphocytes. J. Exp. Med. 152, 1070-1084. doi: 10.1084/ jem.152.4.1070

O’Loughlin, A. J., Mäger, I., de Jong, O. G., Varela, M. A., Schiffelers, R. M., El Andaloussi, S., et al. (2017). Functional Delivery of Lipid-Conjugated siRNA by Extracellular Vesicles. Mol. Ther. 25, 1580-1587. doi: 10.1016/j. ymthe.2017.03.021
Palucka, K., and Banchereau, J. (2013). Dendritic-cell-based therapeutic cancer vaccines. Immunity 39, 38-48. doi: 10.1016/j.immuni.2013.07.004

Pariset, E., Agache, V., and Millet, A. (2017). Extracellular vesicles: isolation methods. Adv. Biosyst. 1, 1700040. doi: 10.1002/adbi.201700040

Peng, P., Yan, Y., and Keng, S. (2011). Exosomes in the ascites of ovarian cancer patients: Origin and effects on anti-tumor immunity. Oncol. Rep. 25, 749-762. doi: 10.3892/or.2010.1119

Petersen, K. E., Manangon, E., Hood, J. L., Wickline, S. A., Fernandez, D. P., Johnson, W. P., et al. (2014). A review of exosome separation techniques and characterization of B16-F10 mouse melanoma exosomes with AF4UV-MALS-DLS-TEM. Anal. Bioanal. Chem. 406, 7855-7866. doi: 10.1007/ s00216-014-8040-0

Petrova, N. S., Chernikov, I. V., Meschaninova, M. I., Dovydenko, I. S., Venyaminova, A. G., Zenkova, M. A., et al. (2012). Carrier-free cellular uptake and the gene-silencing activity of the lipophilic siRNAs is strongly affected by the length of the linker between siRNA and lipophilic group. Nucleic Acids Res. 40, 2330-2344. doi: 10.1093/nar/gkr1002

Pitt, J. M., André, F., Amigorena, S., Soria, J. C., Eggermont, A., Kroemer, G., et al. (2016). Dendritic cell-derived exosomes for cancer therapy. J. Clin. Invest. 126, 1224-1232. doi: 10.1172/JCI81137

Pitt, J. M., Charrier, M., Viaud, S., Andre, F., Besse, B., Chaput, N., et al. (2014). Dendritic cell-derived exosomes as immunotherapies in the fight against cancer. J. Immunol. 193, 1006-1011. doi: 10.4049/jimmunol.1400703

Rekker, K., Saare, M., Roost, A. M., Kubo, A. L., Zarovni, N., Chiesi, A., et al. (2014). Comparison of serum exosome isolation methods for microRNA profiling. Clin. Biochem. 47, 135-138. doi: 10.1016/j.clinbiochem.2013.10.020

Rizzo, M. M., Alaniz, L., and Mazzolini, G. (2014). "Ex vivo loading of autologous dendritic cells with tumor antigens," in Methods in Molecular Biology. Eds. M. J. P. Lawman and P. D. Lawman (New York, NY: Springer New York), 41-44. doi: 10.1007/978-1-4939-0345-0_5

Romani, N., Gruner, S., Brang, D., Käimpgen, E., Lenz, A., Trockenbacher, B., et al. (1994). Proliferating dendritic cell progenitors in human blood. J. Exp. Med. 180, 83-93. doi: 10.1084/jem.180.1.83

Sallusto, B. F., Cella, M., Danieli, C., and Lanzavecchia, A. (1995). Efficient presentation of soluble antigen by cultured human dendritic cells is maintained by granulocyte/macrophage colony-stimulating factor plus interleukin 4 and downregulated by tumor necrosis factor $\alpha$. J. Exp. Med. 182, 389-400. doi: 10.1084/jem.182.2.389

Savina, A., and Amigorena, S. (2007). Phagocytosis and antigen presentation in dendriticcells. Immunol. Rev. 219, 143-156. doi: 10.1111/j.1600-065X.2007.00552.x

Seo, N., Akiyoshi, K., and Shiku, H. (2018). Exosome-mediated regulation of tumor immunology. Cancer Sci. 109, 2998-3004. doi: 10.1111/cas.13735

Shen, Y., Guo, D., Weng, L., Wang, S., Ma, Z., Yang, Y., et al. (2017). Tumorderived exosomes educate dendritic cells to promote tumor metastasis via HSP72/HSP105-TLR2/TLR4 pathway. Oncoimmunology 6, 1-16. doi: 10.1080/2162402X.2017.1362527

Shtam, T. A., Kovalev, R. A., Varfolomeeva, E. Y., Makarov, E. M., Kil, Y. V., and Filatov, M. V. (2013). Exosomes are natural carriers of exogenous siRNA to human cells in vitro. Cell Commun. Signal. 11, 1-10. doi: 10.1186/1478-811X-11-88

Sobo-Vujanovic, A., Munich, S., and Vujanovic, N. L. (2014). Dendritic-cell exosomes cross-present Toll-like receptor-ligands and activate bystander dendritic cells. Cell. Immunol. 289, 119-127. doi: 10.1016/j.cellimm.2014.03.016

Soung, Y. H., Ford, S., Zhang, V., and Chung, J. (2017). Exosomes in cancer diagnostics. Cancers (Basel). 9, 8. doi: 10.3390/cancers 9010008

Steinman, R. M., and Cohn, Z. A. (1973). Identification of a novel cell type in peripheral lymphoid organs of mice. I. Morphology, quantitation, tissue distribution. J. Exp. Med. 137, 1142-1162. doi: 10.1084/jem.137.5.1142

Stremersch, S., Vandenbroucke, R. E., Van Wonterghem, E., Hendrix, A., De Smedt, S. C., and Raemdonck, K. (2016). Comparing exosome-like vesicles with liposomes for the functional cellular delivery of small RNAs. J. Control. Release 232, 51-61. doi: 10.1016/j.jconrel.2016.04.005

Szajnik, M., Czystowska, M., Szczepanski, M. J., Mandapathil, M., and Whiteside, T. L. (2010). Tumor-derived microvesicles induce, expand and up-regulate biological activities of human regulatory T cells (Treg). PLoS One 5, e11469. doi: 10.1371/journal.pone.0011469

Szczepanski, M. J., Szajnik, M., Welsh, A., Whiteside, T. L., and Boyiadzis, M. (2011). Blast-derived microvesicles in sera from patients with acute myeloid 
leukemia suppress natural killer cell function via membrane-associated transforming growth factor- $\beta 1$. Haematologica 96, 1302-1309. doi: 10.3324/ haematol.2010.039743

Tang, Y. T., Huang, Y. Y., Zheng, L., Qin, S. H., Xu, X. P., An, T. X., et al. (2017). Comparison of isolation methods of exosomes and exosomal RNA from cell culture medium and serum. Int. J. Mol. Med. 40, 834-844. doi: 10.3892/ijmm.2017.3080

Théry, C., Zitvogel, L., and Amigorena, S. (2002). Exosomes: composition, biogenesis and function. Nat. Rev. Immunol. 2, 569-579. doi: 10.1038/nri855

Tian, Y., Li, S., Song, J., Ji, T., Zhu, M., Anderson, G. J., et al. (2014). A doxorubicin delivery platform using engineered natural membrane vesicle exosomes for targeted tumor therapy. Biomaterials 35, 2383-2390. doi: 10.1016/j. biomaterials.2013.11.083

Tkach, M., Kowal, J., Zucchetti, A. E., Enserink, L., Jouve, M., Lankar, D., et al. (2017). Qualitative differences in T-cell activation by dendritic cell-derived extracellular vesicle subtypes. EMBO J. 36, 3012-3028. doi: 10.15252/embj.201696003

Usman, W. M., Pham, T. C., Kwok, Y. Y., Vu, L. T., Ma, V., Peng, B., et al. (2018). Efficient RNA drug delivery using red blood cell extracellular vesicles. Nat. Commun. 40, e130. doi: 10.1038/s41467-018-04791-8

Van den Boorn, J. G., Daßler, J., Coch, C., Schlee, M., and Hartmann, G. (2013). Exosomes as nucleic acid nanocarriers. Adv. Drug Deliv. Rev. 65, 331-335. doi: 10.1016/j.addr.2012.06.011

Van Willigen, W. W., Bloemendal, M., Gerritsen, W. R., Schreibelt, G., De Vries, I. J. M., and Bol, K. F. (2018). Dendritic cell cancer therapy: vaccinating the right patient at the right time. Front. Immunol. 9, 1-13. doi: 10.3389/ fimmu.2018.02265

Viaud, S., Terme, M., Flament, C., Taieb, J., André, F., Novault, S., et al. (2009). Dendritic cell-derived exosomes promote natural killer cell activation and proliferation: a role for NKG2D ligands and IL-15Ra. PLoS One 4(3), e4942. doi: 10.1371/journal.pone.0004942

Viaud, S., Théry, C., Ploix, S., Tursz, T., Lapierre, V., Lantz, O., et al. (2010). Dendritic cell-derived exosomes for cancer immunotherapy: what's next? Cancer Res. 70, 1281-1285. doi: 10.1158/0008-5472.CAN-09-3276

Wahlgren, J., Karlson, T. D. L., Brisslert, M., Vaziri Sani, F., Telemo, E., Sunnerhagen, P., et al. (2012). Plasma exosomes can deliver exogenous short interfering RNA to monocytes and lymphocytes. Nucleic Acids Res. 40, e130. doi: $10.1093 / \mathrm{nar} / \mathrm{gks} 463$

Wahlund, C. J. E., Güclüler, G., Hiltbrunner, S., Veerman, R. E., Näslund, T. I., and Gabrielsson, S. (2017). Exosomes from antigen-pulsed dendritic cells induce stronger antigen-specific immune responses than microvesicles in vivo. Sci. Rep. 7, 1-9. doi: 10.1038/s41598-017-16609-6

Wan, Y., Wang, L., Zhu, C., Zheng, Q., Wang, G., Tong, J., et al. (2018). Aptamerconjugated extracellular nanovesicles for targeted drug delivery. Cancer Res. 78, 798-808. doi: 10.1158/0008-5472.CAN-17-2880

Wang, B., Yao, K., Huuskes, B. M., Shen, H. H., Zhuang, J., Godson, C., et al. (2016). Mesenchymal stem cells deliver exogenous MicroRNA-let7c via exosomes to attenuate renal fibrosis. Mol. Ther. 24, 1290-1301. doi: 10.1038/mt.2016.90

Wang, J., Wang, L., Lin, Z., Tao, L., and Chen, M. (2014). More efficient induction of antitumor $\mathrm{T}$ cell immunity by exosomes from CD40L gene-modified lung tumor cells. Mol. Med. Rep. 9, 125-131. doi: 10.3892/mmr.2013.1759

Wang, J., Wang, Z., Mo, Y., Zeng, Z., Wei, P., and Li, T. (2015). Effect of hyperthermic $\mathrm{CO} 2$-treated dendritic cell-derived exosomes on the human gastric cancer AGS cell line. Oncol. Lett. 10, 71-76. doi: 10.3892/ol.2015.3155

Wang, L., Xie, Y., Ahmed, K. A., Ahmed, S., Sami, A., Chibbar, R., et al. (2013). Exosomal pMHC-I complex targets $\mathrm{T}$ cell-based vaccine to directly stimulate CTL responses leading to antitumor immunity in transgenic FVBneuN and HLAA2/HER2 mice and eradicating trastuzumab-resistant tumor in athymic nude mice. Breast Cancer Res. Treat. 140, 273-284. doi: 10.1007/s10549-013-2626-7

Wang, Y., Chen, X., Tian, B., Liu, J., Yang, L., Zeng, L., et al. (2017). Nucleolintargeted extracellular vesicles as a versatile platform for biologics delivery to breast cancer. Theranostics 7, 1360-1372. doi: 10.7150/thno.16532

Whiteside, T. L. (2016a). Exosomes and tumor-mediated immune suppression. J. Clin. Invest. 126, 1216-1223. doi: 10.1172/JCI81136

Whiteside, T. L. (2016b). Tumor-derived exosomes and their role in cancer progression. Adv. Clin. Chem. 74, 103-141. doi: 10.1016/bs.acc.2015.12.005

Wieckowski, E. U., Visus, C., Szajnik, M., Szczepanski, M. J., Storkus, W. J., and Whiteside, T. L. (2009). Tumor-derived microvesicles promote regulatory
T cell expansion and induce apoptosis in tumor-reactive activated CD8 + T lymphocytes. J. Immunol. 183, 3720-3730. doi: 10.4049/jimmunol.0900970

Wiklander, O. P. B., Nordin, J. Z., O'Loughlin, A., Gustafsson, Y., Corso, G., Mäger, I., et al. (2015). Extracellular vesicle in vivo biodistribution is determined by cell source, route of administration and targeting. J. Extracell. Vesicles 4, 1-13. doi: 10.3402/jev.v4.26316

Wolfers, J., Lozier, A., Raposo, G., Regnault, A., Théry, C., Masurier, C., et al. (2001). Tumor-derived exosomes are a source of shared tumor rejection antigens for CTL cross-priming. Nat. Med. 7, 297-303. doi: 10.1038/85438

Xiang, X., Poliakov, A., Liu, C., Liu, Y., Deng, Z., Wang, J., et al. (2009). Induction of myeloid-derived suppressor cells by tumor exosomes. Int. J. Cancer 124, 2621-2633. doi: 10.1002/ijc.24249

Yamada, T., Inoshima, Y., Matsuda, T., and Ishiguro, N. (2012). Comparison of Methods for Isolating Exosomes from Bovine Milk. J. Vet. Med. Sci. 74, 15231525. doi: 10.1292/jvms.12-0032

Yang, C., Kim, S. H., Bianco, N. R., and Robbins, P. D. (2011). Tumor-derived exosomes confer antigen-specific immunosuppression in a murine delayed-type hypersensitivity model. PLoS ONE 6, e22517. doi: 10.1371/journal.pone.0022517

Yao, Y., Chen, L., Wei, W., Deng, X., Ma, L., and Hao, S. (2013). Tumor cell-derived exosome-targeted dendritic cells stimulate stronger CD8+CTL responses and antitumor immunities. Biochem. Biophys. Res. Commun. 436, 60-65. doi: 10.1016/j.bbrc.2013.05.058

Yao, Y., Wang, C., Wei, W., Shen, C., Deng, X., Chen, L., et al. (2014). Dendritic cells pulsed with leukemia cell-derived exosomes more efficiently induce antileukemic immunities. PLoS ONE 9, e91463. doi: 10.1371/journal. pone.0091463

Yu, S., Liu, C., Su, K., Wang, J., Liu, Y., Zhang, L., et al. (2007). Tumor Exosomes Inhibit Differentiation of Bone Marrow Dendritic Cells. J. Immunol. 178, 68676875. doi: 10.4049/jimmunol.178.11.6867

Zeelenberg, I. S., Ostrowski, M., Krumeich, S., Bobrie, A., Jancic, C., Boissonnas, A., et al. (2008). Targeting tumor antigens to secreted membrane vesicles in vivo induces efficient antitumor immune responses. Cancer Res. 68, 1228-1235. doi: 10.1158/0008-5472.CAN-07-3163

Zhang, D., Lee, H., Wang, X., Rai, A., Groot, M., and Jin, Y. (2018). Exosomemediated small RNA delivery: a novel therapeutic approach for inflammatory lung responses. Mol. Ther. 26, 2119-2130. doi: 10.1016/j.ymthe.2018.06.007

Zhang, D., Lee, H., Zhu, Z., Minhas, J. K., and Jin, Y. (2017). Enrichment of selective miRNAs in exosomes and delivery of exosomal miRNAs in vitro and in vivo. Am. J. Physiol. Lung Cell Mol. Physiol. 312, L110-L121. doi: 10.1152/ ajplung.00423.2016

Zhang, H., Tang, K., Zhang, Y., Ma, R., Ma, J., Li, Y., et al. (2014a). Cell-free tumor microparticle vaccines stimulate dendritic cells via cGAS/STING Signaling. Cancer Immunol. Res. 3, 196-205. doi: 10.1158/2326-6066.CIR-14-0177

Zhang, Y., Li, L., Yu, J., Zhu, D., Zhang, Y., Li, X., et al. (2014b). Microvesiclemediated delivery of transforming growth factor $\beta 1$ siRNA for the suppression of tumor growth in mice. Biomaterials 35, 4390-4400. doi: 10.1016/j. biomaterials.2014.02.003

Zhong, H., Yang, Y., Ma, S., Xiu, F., Cai, Z., Zhao, H., et al. (2011). Induction of a tumour-specific CTL response by exosomes isolated from heat-treated malignant ascites of gastric cancer patients. Int. J. Hyperth. 27, 604-611. doi: $10.3109 / 02656736.2011 .564598$

Zhou, M., Chen, J., Zhou, L., Chen, W., Ding, G., and Cao, L. (2014). Pancreatic cancer derived exosomes regulate the expression of TLR4 in dendritic cells via miR-203. Cell Immunol. 292, 65-69. doi: 10.1016/j.cellimm.2014.09.004

Conflict of Interest: The authors declare that the research was conducted in the absence of any commercial or financial relationships that could be construed as a potential conflict of interest.

Copyright () 2019 Markov, Oshchepkova and Mironova. This is an open-access article distributed under the terms of the Creative Commons Attribution License (CC BY). The use, distribution or reproduction in other forums is permitted, provided the original author(s) and the copyright owner(s) are credited and that the original publication in this journal is cited, in accordance with accepted academic practice. No use, distribution or reproduction is permitted which does not comply with these terms. 